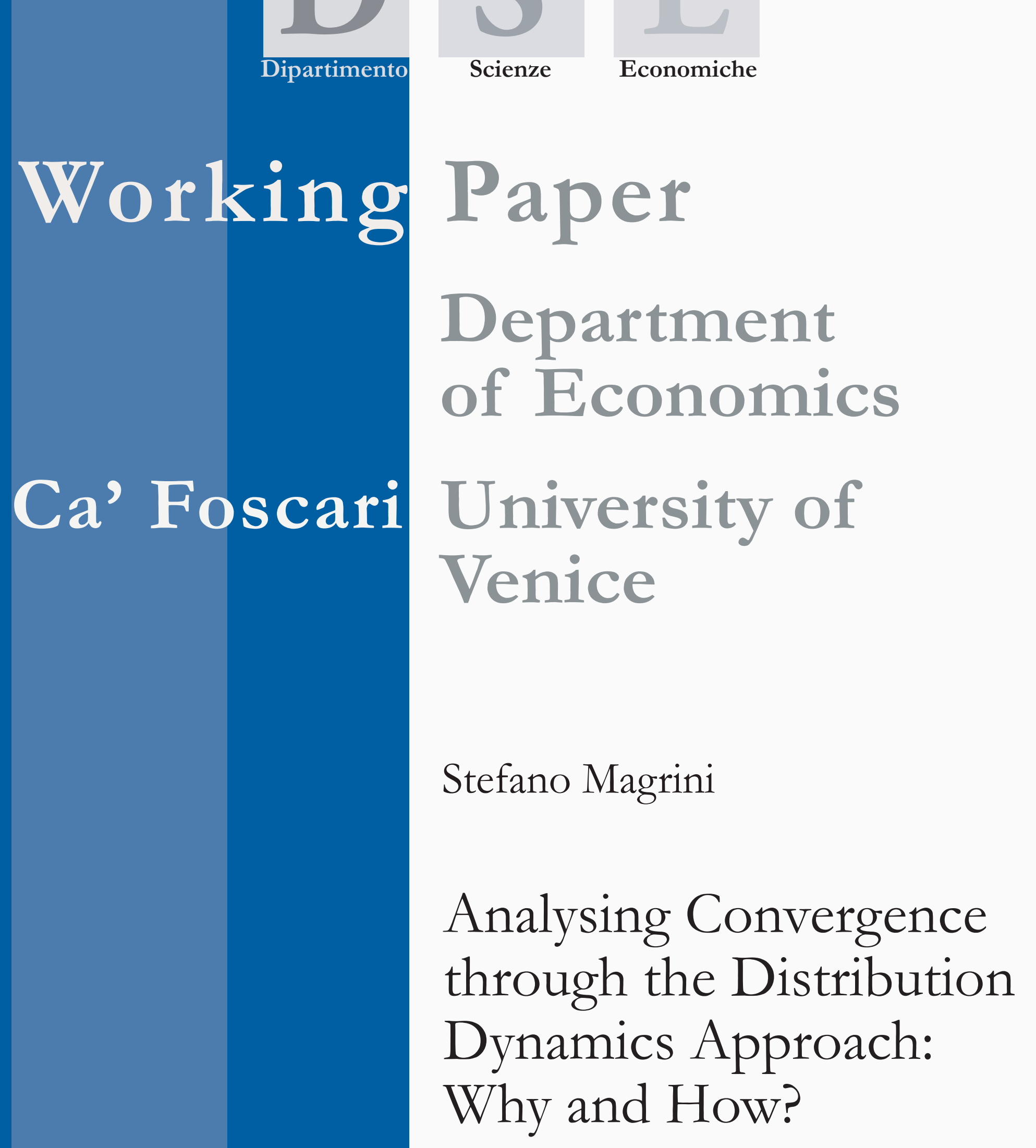




\title{
Analysing Convergence through the Distribution Dynamics Approach: Why and How?
}

\author{
Stefano Magrini \\ University of Venice
}

First Draft: September 2007

\begin{abstract}
The convergence hypothesis has stimulated a heated debate within the growth literature. The present paper compares the two most commonly adopted empirical approaches, the regression approach and the distribution dynamics approach, and argues that the former fails to uncover important features of the dynamics that might characterise the convergence process. Next, it provides an in depth description of the features and underlying assumptions of the distribution dynamics approach as well as a detailed discussion of some important aspects related to the estimate of stochastic kernels via kernel density estimators. Finally, the empirical section allows to emphasises the interpretational advantages stemming from the use of stochastic kernels to capture the evolution of the entire crosssectional income distribution. Incidentally, through a comparison between the results obtained from alternative sets of Italian regions, it suggest that the use of administrative regions could lead to ambiguous results.
\end{abstract}

\section{Keywords}

Distribution Dynamics, Stochastic Kernel, Kernel Density Estimation, $\beta$-convergence, Regions

\section{JEL Codes}

C14, C20, O40, O52, R10

\author{
Address for correspondence: \\ Stefano Magrini \\ Department of Economics \\ Ca' Foscari University of Venice \\ Cannaregio 873, Fondamenta S.Giobbe \\ 30121 Venezia - Italy \\ Phone: (++39) 0412349194 \\ Fax: $(++39) 0412349176$ \\ e-mail: s.magrini@unive.it
}

This Working Paper is published under the auspices of the Department of Economics of the Ca' Foscari University of Venice. Opinions expressed herein are those of the authors and not those of the Department. The Working Paper series is designed to divulge preliminary or incomplete work, circulated to favour discussion and comments. Citation of this paper should consider its provisional character.

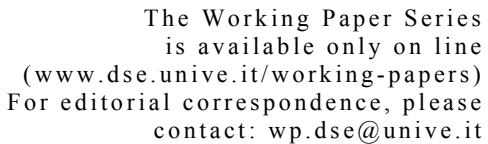

Department of Economics

Ca' Foscari University of Venice

Cannaregio 873 , Fondamenta San Giobbe

30121 Venice Italy

Fax: ++390412349210 


\section{Analysing Convergence through the Distribution Dynamics Approach: Why and How?}

\section{$1 \quad$ Introduction}

Convergence is a basic empirical issue and, particularly within the economic growth literature, its analysis has stimulated a wide-ranging and rather heated debate. Two broad threads of analysis have emerged. Within the first thread - the regression approach - a variety of methods has been adopted to test the convergence predictions of the traditional neoclassical model of growth. Initial attempts, following the seminal contribution by Baumol (1986) subsequently refined by Barro (1991) and Barro and Sala-i-Martin (1991 and 1992), have made use of cross-sectional data. Later, in order to allow for unobserved heterogeneities and to deal with endogeneity concerns, panel data methods have been adopted. In fewer cases, time series data methods entailing the notions of unit roots and cointegration have instead been employed. In essence, all these methods aim at verifying whether economies converge towards steady state paths by testing the existence of a negative correlation between the initial level of per capita income and subsequent growth or, as is commonly known, $\beta$-convergence. However, it has soon been recognised that a negative relationship between growth rates and initial values is a necessary, but not a sufficient, condition for a reduction in the crosssectional dispersion of per capita income over time, commonly indicated as $\sigma$-convergence. Consequently, proponents of the regression approach have suggested that, in order to properly analyse converge across economies, the study of $\beta$-convergence should be complemented by the study of $\sigma$-convergence (Sala-i-Martin, 1996). Advocates of this approach then maintain that while $\beta$-convergence allows to examine the degree of mobility within the cross-sectional distribution, through $\sigma$-convergence it is possible to see whether per capita income levels across the economies are becoming increasingly similar.

The second thread of analysis - the distribution dynamics approach - contends this view explicitly. Following the work of Quah (1993a, 1996a and 1997), a number of researchers have argued that the regression approach is substantially uninformative: due to its emphasis on the behaviour of a representative economy, it fails to reveal the dynamics of the entire cross-sectional distribution or, put it differently, to provide information on how one part of the distribution behaves with respect to another. In contrast, the newer approach examines directly the cross-sectional distribution of per capita income. In particular, it resorts to stochastic kernels to capture the behaviour of the entire cross-sectional income distribution as it evolves over time, providing information on both the change in its external shape and on intra-distribution dynamics.

As in previous papers (Magrini, 1999 and 2004), here I will follow this second approach and try to contribute to the debate in two ways. Firstly, I will emphasise the inadequacies of the regression approach in comparison with the distribution dynamics approach through some empirical examples that use both real and simulated data. In the opening example, using data generated ad hoc in order to produce a complex set of dynamics, I will show that the regression approach fails to uncover the tendency towards the formation of two distinct convergence clubs. These dynamics are instead unambiguously revealed through the estimate of a stochastic kernel. The subsequent examples, in which I use data on Gross Value Added 
per capita for two different sets of Italian regions, confirm that the uninformative and potentially misleading representation of the convergence process provided by the regression approach is not just a purely theoretical possibility. Incidentally, I will also suggest that the use of administratively defined regions could lead to ambiguous conclusions.

Secondly, in order to stimulate the debate on the distribution dynamics approach and to encourage its adoption in convergence studies, I will provide a rather in depth description of its features and underlying assumptions as well as a detailed discussion of some important aspects related to the estimate of stochastic kernels via kernel density estimators. Given their rather technical nature, and to avoid to make the presentation excessively heavy, these estimation issues will be confined to a Technical Appendix, which will also offer an overview of the basic features of the Matlab code employed in the empirical analysis and freely downloadable, together with the data, from the author's web site.

The rest of the paper is organised as follows. Section 2 provides an outline of the theoretical foundations of the regression approach and of the different methods that have been adopted for its practical implementation. Section 3 examines some major critical remarks that have been raised in the literature with respect to the regression approach. Then, Section 4 turns to the distribution dynamics approach, describes its general features and, in combination with the Technical Appendix, explains the way in which it can be put into practice. Some empirical examples are presented in Section 5, where the results obtained through the application of the two alternative approaches to real and simulated data are compared. Section 6 briefly concludes.

\section{The regression approach}

As is well known, the regression approach has its theoretical foundations in the traditional neoclassical model of growth originally set out by Solow (1956) and Swan (1956), and subsequently refined by Cass (1965) and Koopmans (1965), following the work of Ramsey (1928). Its main features can be summarised as follows (see, among many others, Barro and Sala-i-Martin, 1995 for a detailed description).

Consider a closed economic system in which physical capital $(K)$ and labour $(L)$ are employed in the production of a homogeneous consumption good $(Y)$ using a (twice differentiable, homogeneous of degree 1, increasing, jointly concave in all its arguments and strictly concave in each) production function.

Define the effective amount of labour as $\mathcal{L}=L A(t)$, where the level of technology $A(t)$ grows exponentially at the exogenously given rate $\mu: A(t)=A(0) \mathrm{e}^{\mu t}$. Defining now physical capital and output per unit of effective labour as $\tilde{y} \equiv Y / \widetilde{L}$ and $\widetilde{k} \equiv K / \widetilde{L}$, the production function that includes labour-augmenting technological progress can then represented as

$$
\tilde{y}=f(\widetilde{k}) \text {. }
$$

Under either the Solow-Swan accumulation framework - in which an exogenously given fraction of output is saved and invested in new physical capital while the remaining output is consumed - or the Cass-Koopmans framework - in which rational households with perfect 
foresight choose the consumption path, and thus the saving path, by maximising intertemporal utility subject to a flow budget constraint - the system exhibits saddle-path stability (Barro and Sala-i-Martin 1995, Durlauf and Quah 1999). The economy thus converges to a steady state equilibrium in which the level of income per capita, consumption per capita and the capital-labour ratio all grow at the exogenous rate of technological progress while variables per unit of effective labour are constant.

Testable implications for the convergence debate are then derived from the transitional dynamics of the model with Cobb-Douglass technology. In particular, considering observed per capita income $y=\tilde{y} A$, a Taylor series approximation of the system's dynamics around the deterministic steady state yields:

$$
\log y(t)=[\log y(0)-(\log g / x+\log A(0))] \mathrm{e}^{-\beta t}+[\log g / x+\log A(0)+\mu t]
$$

where $y(0)$ is the level of output per worker at an initial time $0, \tilde{y}^{*}$ is the level of output per unit of effective labour that will be reached in the steady state, while the parameter $\beta$ describes the speed with which the economy converges towards its steady state. ${ }^{1}$ According to this equation, the log of per capita income can therefore be viewed as having two components: a convergence component (the first term of the right-hand side) and a levels component (the rest of the right-hand side). Figure 1, in which different steady state paths corresponding to two possible values for the sum $\log y *+\log A(0)$ have been exemplified, shows that, as long as this sum remains unobserved or unrestricted, any pattern of crosssectional convergence is consistent with the model.

\section{[Figure 1 around here]}

Moving to growth rates, the average growth rate of observed per capita income over an interval of $t \geq 0$ time periods starting at 0 can be expressed as

$$
(1 / t) \log [y(t) / y(0)]=\mu+\left(1-\mathrm{e}^{-\beta t}\right) / t \cdot[\log \beta / x+\log A(0)]-\left(1-\mathrm{e}^{-\beta t}\right) / t \cdot \log y(0)
$$

stating that, other things being equal, the average growth rate of per capita income depends negatively on its initial level, conditioned on the exogenous growth rate of technology, on the steady state value of income per effective worker, and on the initial level of technology.

Since the exact value of these conditioning factors is unknown, Barro and Sala-i-Martin (1991 and 1992) suggest using the following growth equation:

$$
(1 / t) \log [y(t) / y(0)]=c-\left(1-\mathrm{e}^{-\beta t}\right) / t \cdot \log y(0)+u(t)
$$

where $u(t)$ is a random disturbance while the constant $c$ summarises the unobserved parameters.

As anticipated, the key parameter to be empirically estimated is the speed of convergence to the steady state, $\beta$, i.e. the rate at which the representative economy approaches its steady state growth path. Consequently, this way of analysing convergence across economies is commonly known as $\beta$-convergence. Moreover, the nature of the convergence process is often

\footnotetext{
$1 \quad$ Within the framework described here, the convergence speed depends on the capital-share coefficient: as the latter tends to one, so that diminishing returns to capital no longer apply, the speed of convergence tends to zero.
} 
analysed through a second parameter, the so-called "half-life", which can be computed from the estimated value for $\beta$ according to

$$
\text { half-life } \equiv \frac{\log 2}{\beta}
$$

and provides a measure of the time the representative economy needs to halve the gap between initial and steady state levels.

Following the work of Baumol (1986), Barro and Sala-i-Martin (1991 and 1995), Mankiw et al. (1992) and Sala-i-Martin (1996), applications of this approach to national and regional data are extremely abundant. Since a number of surveys of this literature already exist (see, among others, Durlauf and Quah, 1999; Temple, 1999; Islam, 2003; Magrini, 2004; Abreu et al. $2005 \mathrm{a}$ and b; Durlauf et al., 2005), only a very brief account will be given here.

\subsection{Cross-sectional data}

A first way of obtaining estimates of the convergence rate parameter applies ordinary leastsquares (OLS) to cross-sectional data. In particular, when convergence is examined across a group of homogenous economic systems - i.e. a group that, being characterised by similar technological levels and institutional environments, therefore shares the same steady state unconditional (or absolute) convergence is expected and Equation (2.1) can be applied directly. In contrast, when the economies differ in technological levels and attitudes toward saving, the group will show multiple steady states; under these circumstances the neoclassical model invokes the concept of conditional convergence. From an operational point of view, this requires the introduction of additional explanatory variables that represent proxies for the different steady states in the cross-sectional growth regression (2.1). The growth equation thus becomes

$$
(1 / t) \log [y(t) / y(0)]=c-\left(1-e^{-\beta t}\right) / t \cdot \log y(0)+\mathbf{z}^{\prime} \boldsymbol{\alpha}+u(t)
$$

where $\mathbf{z}$ is a vector of additional explanatory variables that accounts for differences in the steady state values of per capita income across economies.

A large number of empirical studies applying OLS to cross-section data has found estimates of the convergence rate of about $2 \%$. In fact, some variation in the estimated values can be found, but the range is rather contained (usually between $1 \%$ and $3 \%$ ) so that this convergence rate has become popular as the " $2 \%$ rule" (Sala-i-Martin, 1996). However, a number of authors (Rey and Montuori, 1999; Baumont, Ertur and Le Gallo, 2003; Florax and Nijkamp, 2005, Abreu et al., 2005 a and b) have recently emphasised that statistical inference based on OLS estimates of Equation (2.2) becomes unreliable ${ }^{2}$ in the presence of spatial effects (Anselin, 1988; Anselin and Rey, 1991). As pointed out by Rey and Montuori (1999), the literature on spatial econometrics offers a rich set of procedures for testing for the presence of spatial effects and suggests a number of estimators for models that treat spatial effects explicitly within the cross-sectional regression approach (Anselin, 1988; Anselin, 1995; Anselin and Bera, 1998; Anselin and Florax, 1995; Anselin and Rey, 1991; Anselin et al., 1996; Getis and Ord, 1992). Applying these techniques to US regional income data and, in particular, estimating a spatial error model, these authors find a lower rate of convergence than that based on OLS.

2 More specifically, in the case of spatial autocorrelation in the error term, the OLS estimator is biased but inefficient; in contrast, when spatial autocorrelation pertains to the dependent variable, the OLS estimator is biased and inconsistent. 


\subsection{Panel data}

A second popular way of estimating growth regressions is represented by panel data methods. As previously noted, conditional cross-sectional convergence analyses must allow for steady state income determinants in order to provide consistent estimates. Given that some of these determinants might be unknown or unmeasurable, it is argued that the way to obtain consistent estimates is to use panel data methods.

The simplest fixed effects panel data model of the convergence process would then be:

$$
\log [y(t) / y(t-1)]=c_{0}+c_{1}(t)-b \log y(t-1)+u(t)
$$

showing that the original constant $c$ is now decomposed into an unobservable economyspecific effect (which is constant over time and determines the region's steady state) $c_{0}$, and a time-specific effect, $c_{1}$, affecting all economies. For the estimation, the least-squares dummy variable estimator (Hsiao, 1986) was initially applied. However, since this estimator is consistent only for a large number of observations over time (Nickell, 1981), the most widely adopted alternative is the first-differenced Generalised Method of Moments (GMM) estimator suggested by Arellano (1988) and Arellano and Bond (1991) and introduced into the growth literature by Caselli, et al. (1996).

In general, estimates of the convergence rate from fixed effects panel data models tend to be substantially higher than the $2 \%$ typical result from cross-sectional studies. However, more recently Bond et al. (2001) emphasise that the first-differenced GMM estimator may be subject to a large finite-sample bias when the time series are persistent - as is usually the case with output series - and short, so that lagged levels of the variables are weak instruments for subsequent first-differences. They thus suggest a system GMM estimator (Arellano and Bover, 1995; Blundell and Bond, 1998) using which they obtain convergence rates in line with the cross-sectional estimates.

Similar to the cross-sectional case, also within the panel data setting there has recently been a greater attention to the consequences of spatial effects and to the development of spatial econometric models. Badinger et al. (2004) propose a two-step procedure in which a system GMM for dynamic panels is used after a spatial filtering technique is employed in order to remove existing spatial correlation. Following Elhorst (2001 and 2003), who discusses specification and estimation issues of panel data models that include spatial effects, Arbia and Piras (2005) instead estimate a fixed effects panel data model that allows for spatial autocorrelation in the error term while Arbia, Basile and Piras (2005) extend the fixed effect model to include also a spatially lagged dependent variable. A further development is represented by the analysis of Arbia, Elhorst and Piras (2005) in which the convergence rate is estimated via a dynamic spatial panel model as in Elhorst (2005).

\subsection{Time series data}

The last way to implement the regression approach is via time series methods in which the definition of convergence relies on the notions of unit roots and cointegration. One of these methods has been developed by Bernard and Durlauf (1995 and 1996) according to whom convergence in output is defined as the equality across economies of long-term forecasts of per capita income taken at a given fixed date. In particular, if we denote with $I_{t}$ the information set at time $t$, two economies $i$ and $j$ are said to exhibit stochastic convergence if the long run forecasts of output are equal: 


$$
\lim _{k \rightarrow \infty} E\left(y_{i, t+k}-y_{j, t+k} \mid I_{t}\right)=0
$$

As described in Bernard and Durlauf (1996), convergence in a time series data setting is analysed by checking the compatibility of $y_{i, t}-y_{j, t}$ with a time invariant Wold representation of the form:

$$
y_{i, t}-y_{j, t}=\kappa_{i, j}+\sum_{r=0}^{\infty} \pi_{i, j, r} \varepsilon_{i, j, t-r}
$$

such that $\kappa_{i, j}=0$ and $\pi_{i, j, r}$ is square summable. In particular, convergence, as defined by Equations (2.4), requires that $y_{i, t}-y_{j, t}$ is a mean zero stationary process, which can be verified through the application of standard unit roots and cointegration procedures.

The application of time series methodologies to the analysis of convergence has been rather uncommon, particularly within a regional setting where the lack of adequately extended series of data is particularly acute. In general, a large share of these studies reports evidence against convergence, both across countries and regions, which is in contrast with the results from cross-sectional and panel data analyses. A possible explanation for these discrepancies is offered by Bernard and Durlauf (1996) who argue that time series tests are based on a stricter notion of convergence than cross-sectional tests. Indeed, if convergence as catching up (i.e., $\beta$-convergence) between $t$ and $t+s$ is defined as a decrease in the expected deviation in output between economies

$$
E\left(y_{i, t+s}-y_{j, t+s} \mid I_{t}\right)<y_{i, t}-y_{j, t} \quad \text { if } y_{i, t}>y_{j, t}
$$

then, for some fixed $s$, stochastic convergence in Equation (2.4) implies $\beta$-convergence while, obviously, the opposite is not true. ${ }^{3}$

\section{Criticisms to the regression approach}

The regression approach to the analysis of convergence has stimulated the critical attention of many scholars who have emphasised its limitations. In what follows, I will concentrate on what I consider the two most important ones: the problem of open-ended alternatives and the lack of informative content.

First of all, despite being derived directly from the traditional neoclassical model, the crosssectional regression approach is unable to test the validity of this model against alternative and conflicting ones. As clearly pointed out by several authors (Romer, 1993; Fagerberg 1994, Durlauf and Quah, 1999; amongst many others), dynamics such as those illustrated in Figure 1 are implicit in widely different theoretical interpretations of the growth process. Specifically, these interpretations range from the closed-economy, human capital-augmented version of Solow's traditional neoclassical model (Mankiw et al., 1992) to theories of technological diffusion, either within the neoclassical tradition - as the endogenous growth models (Aghion and Howitt, 1992; Grossman and Helpman, 1990; Lucas 1988; Romer, 1986 and $1990 \mathrm{a}$ and $\mathrm{b}$ ) - or within the evolutionary tradition - as the literature on the technological gap (Gerschenkron 1962, Abramovitz, 1986; Fagerberg, 1988). In addition, a set of

\footnotetext{
3 A detailed discussion of this and other issues involved in the implementation of time series test of convergence is beyond the scope of the present paper. The interested reader can refer to the already cited surveys of the literature.
} 
theoretical models explicitly develops cross-sectional dynamics which conform to the behaviour depicted in Figure 1, describing the endogenous formation of convergence clubs based on starting conditions (Azariadis and Drazen, 1990; Durlauf, 1996; Galor and Zeira, 1993; Murphy et al., 1989; Quah, 1996 b and c). To sum up, if our aim is to provide evidence to discriminate between different growth theories, cross-sectional regressions appear of limited use. The regression techniques so far discussed at best produce results which are not inconsistent with neoclassical growth theories. But since they are also consistent with other explanations, they do not constitute a test of traditional neoclassical theory in any scientific sense.

Let us now move to the second, and most discussed, critical aspect of the regression approach: its informative content. First of all, several researchers (Friedman 1992; Quah 1993b; amongst others) emphasise the analogy between regressions of growth rates over initial levels and Galton's fallacy of regression towards the mean. In particular, they demonstrate that a negative relationship between growth rates and initial values ( $\beta$ convergence) does not indicate a reduction in the cross-sectional variance (commonly indicated as $\sigma$-convergence) and, in particular, that it is also possible to observe a diverging cross-sectional distribution even when such a negative relationship holds.

To see this, consider the case in which each economy's growth process is described as in Equation (2.1), in which the error term $u(t)$ is independent and identically distributed in time and has finite variance $\sigma_{u}{ }^{2}>0$. Assume now that $\beta>0$, so that $\beta$-convergence is actually present. Assume further that all $\log y_{i}(0)$ are independent of $u_{i}(t)$ for $\mathrm{t} \geq 1$, and all $\log y$ 's are independent and identically distributed over space ${ }^{4}$ and time. Based on these assumptions, Equation (2.1) then implies: $:^{5}$

$$
\sigma_{t}^{2}=e^{-2 \beta} \sigma_{t-1}^{2}+\sigma_{u t}^{2}
$$

and, as $t$ tends to infinity,

$$
\sigma^{2}=\lim _{t \rightarrow \infty} \sigma_{t}^{2}=\left(1-e^{-2 \beta}\right)^{-1} \sigma_{u}^{2}
$$

As a result, the observed $\beta$-convergence is accompanied by a reduction in cross-sectional convergence, $\sigma$-convergence, if and only if the initial value for the cross-sectional variance, $\sigma_{0}^{2}$, is greater than its steady state value, $\sigma^{2}$. In other words, the regression approach has little informative content: concentrating on the behaviour of a representative economy, the best it can do is to describe how this economy converges to its own steady state; however, it is completely silent on what happens to the entire cross-sectional distribution of economies. But in addition to being uninformative, the regression approach can also be misleading. Within the standard neoclassical approach, dynamics such as those depicted in Figure 1 essentially depend on differences in one or more structural characteristics of each economy, regardless of the starting conditions. In contrast, within theoretical models with the endogenous formation of convergence clubs, these dynamics could be the result of differences in initial conditions across economies with similar structural characteristics. Thus, if a conditioning explanatory variable is not actually determining an economy's economic position as in the standard neoclassical approach but, rather, is evolving endogenously as a response to initial factors

\footnotetext{
$4 \quad$ This implies that also $u(\mathrm{t})$ is independent and identically distributed over space.

This result can be derived by adding $\log y_{i}(t-1)$ to both sides of Equation (2.1), computing the variance, and using the condition that the $\operatorname{cov}\left[u_{i}(t), \log y_{i}(t-1)\right]=0$.
} 
determining club membership, a traditional researcher would incorrectly attribute growth and convergence to the conditioning variable and never discover the true growth determinants. ${ }^{6}$

The fact that a positive coefficient $\beta$ is a necessary but not a sufficient condition for a reduction in the cross-sectional dispersion is acknowledged by Barro and Sala-i-Martin (1991, $1992,1995){ }^{7}$ It is thus suggested that the study of $\beta$-convergence should be complemented by the study of $\sigma$-convergence (Sala-i-Martin, 1996). According to this view, the notion of $\beta$ convergence allows to examine the degree of mobility within the distribution and see how fast poor economies are becoming rich and rich economies poor; in contrast, the notion of $\sigma$ convergence allows to analyse the evolution of the cross-sectional distribution over time and to see whether the economies' incomes are becoming more similar.

However, turning to the concept of $\sigma$-convergence does not represent an effective solution as the analysis of the evolution of the cross-sectional dispersion gives no information on the intra-distributional dynamics. Indeed, it can easily be shown (Quah 1996a) that a constant standard deviation is consistent with very different dynamics ranging from criss-crossing and leap-frogging to persistent inequality and poverty traps. Distinguishing between these dynamics is, however, of essential importance.

\section{$4 \quad$ The distribution dynamics approach}

Firstly suggested by Quah (1993 a and b, 1996 a and b, 1997), the distribution dynamics approach examines directly the evolution of the cross-sectional distribution of per capita income, using stochastic kernels to describe both the change in its external shape and the intra-distribution dynamics.

Consider a group of $n$ economies, indexed by the integer $i$, and suppose time $t$ is continuous with $t \in[0, \infty)$. Then, let $y_{i}(t)$ be the level of per capita income of economy $i$ at time $t$ and $\bar{y}(t)$ the average level of per capita income for the whole group of economies at the same point in time. Next, normalise per capita income with respect to the group average

$$
x_{i}(t) \equiv y_{i}(t) / \bar{y}(t) \quad \text { with } x_{i}(t) \in \mathrm{i}
$$

Through this transformation we are now able to separate the effects on the cross-sectional distribution of aggregate forces from the effect derived from economy-specific forces, having conditioned their aggregate effects out.

\footnotetext{
6 A similar concern is expressed by De la Fuente (2000) who notes that in practice the difference between conditional and unconditional convergence is not totally transparent. If we find that a number of explanatory variables enter significantly in Equation (2.2) we would be tempted to conclude that convergence is only conditional since there are significant differences across economies in their underlying "fundamentals". However, if these variables change over time and tend to converge, it might well be that income is unconditionally converging in the long run.

A positive value for $\beta$ is originally interpreted as an indication of the existence of forces reducing the cross-sectional distribution while ongoing disturbances are seen as forces pushing in the opposite direction. The practical value of this interpretation is however downplayed by Quah (1993a) who observes that even if information about these shocks were used in a cross-sectional regression, still a positive value for $\beta$ would not imply that the variance of the cross-sectional distribution is decreasing.
} 
Next, consider a stochastic process $\{x(t): t \geq 0\}$. Obviously, $x_{i}(t)$ is the level of per capita income of economy $i$ at time $t$ relative to the group average as defined in Equation (4.1). Then, denote by $F_{x(t)}$ the distribution of $x(t)$ and by $f_{x(t)}$ a probability measure associated to $F_{x(t)}$. In particular, assume that the distribution $F_{x(t)}$ admits a density and thus indicate this density with $f_{x(t)}$. $^{8}$

Now, consider a law of motion for these cross-sectional distributions of per capita income. In particular, the dynamics of $\left\{F_{x(t)}: t \geq 0\right\}$, or equivalently of $\left\{f_{x(t)}: t \geq 0\right\}$, can be modelled as an autoregression:

$$
\forall A \subset \mathrm{i}: \quad f_{x(t+s)}(A)=\int_{-\infty}^{\infty} M_{t, s}(x, A) f_{x(t)} d x
$$

where $M_{t, s}$ is a stochastic kernel, mapping the Cartesian product of income values and measurable sets to the interval [0,1]. More explicitly, the stochastic kernel $M_{t, s}$ in Equation (4.2) maps the density at time $t$ into the density at time $t+s$ and tracks where points in $f_{x(t)}$ end up in $f_{x(t+s)}$. Hence, this is the operator upon which attention must be concentrated in order to analyse the dynamics of the entire distribution of per capita income between time $t$ and time $t+s$ : an estimate of $M_{t, s}$ provides information both on the change in the external shape of the distribution and, more importantly, on the movement of the economies from one part of the distribution to another.

How can such an estimate be obtained will be clarified shortly. For the moment, note that no particular assumptions have been made with respect to the properties of the underlying stochastic process $X$. However, if we are prepared to make some assumptions, other valuable information can be obtained from the stochastic kernel. To see this, rewrite Equation (4.2) as the convolution

$$
f_{x(t+s)}=M_{t, s} f_{x(t)}
$$

Then, assume that the stochastic process is Markov so that the conditional probabilities satisfy

$$
\forall x, x_{1}, \ldots, x_{n}: \quad \operatorname{Pr}\left(x(t) \leq x \mid x(t-1)=x_{1}, \ldots, x(t-n)=x_{n}\right)=\operatorname{Pr}\left(x(t) \leq x \mid x(t-1)=x_{1}\right)
$$

Also, assume that the sequence $\left\{M_{t, s}: t \geq 0\right\}$ is time invariant so that, for any $t \geq 0, M_{t, s}=M_{s}$. Due to these two assumptions, if follows that

$$
\forall t, s \quad M_{t+s}=M_{t} M_{s}
$$

Then, iterations of (4.3) yield predictors of future cross-sectional distributions

$$
f_{x(m(t+s))}=\left(M_{s} \ldots M_{s}\right) f_{x(t)}=M_{s}^{m} f_{x(t)}
$$

In addition, if we take Equation (4.4) to the limit as $m \rightarrow \infty$, we obtain a characterisation of the likely long-run cross-sectional distribution of per capita incomes via the long-run (or ergodic) density satisfying

$$
f_{x(\infty)}=M_{s} f_{x(\infty)} \text {. }
$$

We can now turn the attention to the issue of estimating the operator $M_{t, s}$ from cross-sectional data on (relative) per capita income. Let $x$ and $x^{\prime}$ indicate generic values of, respectively, $x(t)$ and $x(t+s)$ and let $p_{t, s}\left(x, x^{\prime}\right)$ be a non-negative measurable function that integrates to 1 .

\footnotetext{
$8 \quad$ This assumption simplifies the presentation without altering the underlying message. For a more general development of the approach see Quah (1996a and b, 1997).
} 
Whenever the stochastic kernel $M_{t, s}(x, A)$ in Equation(4.2) can be defined as the integral of $p\left(x, x^{\prime}\right)$ over the set $A$ :

$$
M_{t, s}(x, A)=\int_{A} p_{t, s}\left(x, x^{\prime}\right) d x^{\prime}
$$

then $p_{t, s}\left(x, x^{\prime}\right)$ is the transition density function associated with the stochastic kernel $M_{t, s}(x, A)$. Consequently, the dynamics of $\left\{f_{t}: t \geq 0\right\}$ in Equation (4.2) become

$$
f_{x(t+s)}\left(x^{\prime}\right)=\int_{-\infty}^{\infty} p_{t, s}\left(x, x^{\prime}\right) f_{x(t)}(x) d x
$$

Finally, solving equation (4.5) for $p_{t, s}$ yields

$$
p_{t, s}\left(x, x^{\prime}\right)= \begin{cases}f_{x(t), x(t+s)}\left(x, x^{\prime}\right) \times f_{x(t)}(x)^{-1} & \text { when } f_{x(t)}(x) \neq 0 \\ 0 & \text { otherwise }\end{cases}
$$

where $f_{x(t),(t+s)}\left(x, x^{\prime}\right)$ denotes the joint probability density function at $x_{i}(t)=x$ and $x_{i}(t+s)=x^{\prime}$.

Hence, as is clear from Equation (4.6), the transition density $p_{t, s}\left(x, x^{\prime}\right)$ is a conditional probability density function, i.e., it is the probability density function of $x_{i}(t+s)=x^{\prime}$, conditional on $x_{i}(t)=x$. Moreover, the equation shows that an estimate of the stochastic kernel can be obtained by dividing the estimate of the joint probability density function $f_{x(t),(t+s)}$ by the estimate of the marginal probability density function $f_{x(t)}$ :

$$
\hat{p}_{t, s}=\hat{f}_{x(t+s) \mid x(t)}=\frac{\hat{f}_{x(t), x(t+s)}}{\hat{f}_{x(t)}}
$$

One possible way of doing this is through the discretisation of the income space, whereby the density estimates in Equation (4.7) can be obtained via a very simple nonparametric density estimator, the histogram. As a consequence of discretisation, the cross-sectional distributions become probability vectors; for the same reason, the stochastic kernel simplifies into a transition probability matrix $P_{t, s}$ whose rows and columns are indexed by the elements of the discretisation, and where each row reports the fraction of economies beginning from that row element and ending up in the different column elements. Assuming that, for all $t \geq 0$, the stochastic process $x(t)$ is Markov and that the transition probability matrix $P_{t, s}$ is time invariant, the model in (4.3) can thus be analysed as a time-homogeneous finite Markov chain. In turn, the evolution of the chain can then be studied through the powers of the timehomogenous transition matrix $P_{s}$. Moreover, if this matrix is irreducible and aperiodic (i.e., the chain is ergodic) then $P_{s}{ }^{k}$ converges elementwise to a matrix in which each column is the unique stationary distribution $f_{x(\infty)}$. Implications for the convergence debate are then drawn either from the analysis of the transition probability matrix or from the study of the stationary distribution. In particular, if $f_{x(\infty)}$ displays a tendency towards a point mass, then we can conclude that there is convergence towards equality. If, on the other hand, the stationary distribution displays a tendency towards a two-point or bimodal measure, one could interpret this as a manifestation of income polarisation. ${ }^{9}$

\footnotetext{
9 It is worth emphasising that the purpose of the study of the stationary distribution - and, hence, the motivation to the Markov and time homogeneity assumptions - is to magnify the dynamics at play during the time span covered by the data, not to derive a forecast of what will happen in the future (see Quah, 1993a, footnote 4). Besides, analogous assumptions are implicitly made in the regression approach when the convergence process is analysed through the parameter $\beta$ and the speed of convergence to the steady state estimated from a regression run over a given time period.
} 
Despite its simplicity, the histogram is quite inefficient statistically compared to other nonparametric density estimators (Scott, 1985). Moreover, as commonly recognised in the literature, discretising a continuous process can distort dynamics in important ways. While Quah (1996a) suggests that the distortion arising from partitioning the income space into five large cells is not likely to conceal the main features of the process, Magrini (1999) adopts a procedure aimed at reducing the degree of arbitrariness in the discretisation by choosing the income grid optimally so as to minimise the (mean-squared or integrated absolute) error of approximation. In contrast, Bulli (1999) recommends adopting a regenerative discretisation method originally employed in the Markov Chain Monte Carlo literature.

Given these critical remarks, a radical alternative is to eschew discretisation and retain a continuous income space. In such a case, the stochastic kernel can be interpreted as a transition matrix with a continuum of rows and columns and the densities in Equation (4.7) can be estimated through kernel density estimators. ${ }^{10}$ Convergence is then analysed directly from the shape of a three-dimensional plot of the stochastic kernel or from the corresponding contour plot. In general, the main diagonal in such graphs highlights persistence properties: when most of the graph is concentrated along this diagonal, then elements in the crosssectional distribution remain where they started. In contrast, a tendency towards convergence to equality would be signalled by a concentration of most of the graph around the 1-value of the time $t+s$ axis and parallel to the time $t$ axis. Finally, the formation of two (or more) separate modes is a signal of a tendency toward polarization (stratification). Additionally, and analogously to the discrete case, if we assume that the process is Markov and time homogeneous, convergence dynamics can be analysed by comparing the features of the stationary distribution to those of the distribution at time $t$.

Before moving to the empirical analysis, a few words on conditioning. As a matter of fact, the distribution dynamics approach described so far, while being able to formalise certain facts about the patterns of cross-sectional growth, does not provide an explanation for them yet. However, the approach can be easily adapted to address this issue by resorting to conditional distributions. To clarify this, suppose for instance that inspection of a kernel estimate of the cross-sectional distribution of per capita income at time $t$ suggests the existence of bimodality. An interesting question would then be whether this feature could be explained by a set of factors. Given that stochastic kernels can be used to relate any two distributions, we can condition a distribution by a set of factors and then look at the stochastic kernel transforming the original (unconditional) distribution to the conditional one. If most of the graph is concentrated around the 1-value of the axis corresponding to conditioned data, and parallel to the unconditioned data axis, this indicates that the chosen set of factors are actually determining the observed bimodality. In addition, conditioned income distributions can also give us information on dynamics. In this case, the effect of the set of factors on convergence dynamics over a $s$-year period starting at year $t$ can be studied analysing directly the estimate of the stochastic kernel mapping the conditional distribution at time $t$ to the corresponding distribution at time $t+s$.

10 The Technical Appendix provides details on kernel density estimators and on the estimating procedure adopted in the empirical part of this paper. An alternative view is offered by Basile (2007) who, following the work of Hyndman et al. (1996) and Hyndman and Yao (2002), argues that the kernel density estimator has undesirable bias properties and proposes alternative conditional density estimators. 
In order to obtain a conditional distribution different forms of conditioning are possible. For instance, when the conditioning variables can be assumed to be exogenous, we can use a simple conditioning scheme (Quah, 1997). In technical terms, given a set of economies $S$, a conditioning scheme $\Psi$ is defined as a collection of triples, one for each economy $i$ in $S$ at time $t$, where each triple is made of:

(i) an integer lag $\tau_{i}(t)$;

(ii) a subset $C_{i}(t)$ of $S$;

(iii) a set of probability weights $w_{i}(t)$ on $S$, never positive outside $C_{i}(t)$.

Within this scheme, the subset $C_{i}(t)$ identifies the collection of economies which are in some form of functional association, based on a theoretically motivated set of factors, with economy $i$ and hence influence its evolution. Moreover, the set of probability weights $w_{i}(t)$ describe the relative strength of each member of the subset in affecting the evolution of $i$, while $\tau_{i}(t)$ represents the delay with which economy $i$ is affected by the development of the economies in $C_{i}(t)$. Finally, if original observations on per capita incomes are represented by $y=\left\{y_{i}(t): i \in S\right.$ and $\left.t \geq 0\right\}$, their conditioned counterparts are defined as

$$
y_{i}(t) \equiv y_{i}(t) / y_{i}(t)
$$

where, for $j \in C_{i}(t)$,

$$
\hat{y}_{i}(t) \equiv \sum_{j} w_{j}(t) y_{i}\left[t-\tau_{i}(t)\right] .
$$

In other words, conditioned observations are simply obtained normalising each region's observations by the weighted average of per capita income in functionally related regions. Alternatively, when the conditioning variables cannot be assumed to be exogenous, a possibility would be to regress per capita income growth rates on a two-sided distributed lag of the conditioning factors and then use the fitted residuals as conditioned observations (Quah, 1996b).

\section{$5 \quad$ Empirical examples}

As I argued in the previous sections, the distribution dynamics approach, describing how the cross-sectional distribution modifies over time and how the economies move from one part of the distribution to another, appears a more informative alternative to the regression approach which, in contrast, concentrates on the transition of a representative economy towards the steady state. Hence, in the present section I will compare the results obtained from the application of the two empirical tools to both real and simulated data. In particular, using two cross-sectional series of per capita income generated ad hoc, I will first magnify the interpretational difficulties that might arise from the lack of informative content characterising the regression approach. Then, in order to emphasise that these difficulties are not unrepresentative of those commonly found using real data, I will analyse convergence in per capita Gross Value Added (GVA) among two sets of Italian regions.

\subsection{A simple simulation exercise}

First of all, I generated two hypothetical cross-sectional series. The first series was obtained by drawing a random sample of 1000 observations from a univariate normal distribution. The second series was instead produced by merging and appropriately sorting two random samples of 500 observations. ${ }^{11}$ Then, in order to ease comparisons with the analysis that will be presented in Section 5.2, I imposed that the mean and the standard deviation of these two

11 These two samples, again drawn from a univariate normal distribution, differed in their means. 
series respectively match - up to the fourth decimal place - those of the logarithm of per capita Gross Value Added observed for the Italian Provinces in 1996 and in 2002. For this reason, I labelled the two series as "1996" and "2002", thus implicitly assuming that the analysis is carried out over a 6-year time period.

We can now turn to the analysis of $\beta$-convergence by looking at Table 1 in which the estimate of Equation (2.1) using Non Linear Least Squares is reported. The estimation results indicate the existence of a process of unconditional convergence across our hypothetical regions. In particular, the estimated value of the rate of convergence towards the common steady state is exactly $2 \%$ and statistically highly significant. The corresponding half-life, i.e. the time needed to halve the gap between initial and steady state levels, is equal to about 35 time periods.

\section{[Table 1 around here]}

As noted before, $\beta$-convergence is a necessary, but not a sufficient condition for the reduction in the dispersion in per capita income, or $\sigma$-convergence. To analyse this second type of convergence, Table 2 reports the standard deviation and the variation coefficient of the two series. Moreover, to formally test the null hypothesis that the variance of the two series is equal, the table also reports two test statistics which have been recently proposed by Carree and Klomp (1997). ${ }^{12}$ Both statistics clearly indicate that the variance has decreased in a statistically significant manner. In other words, we find unambiguous evidence in favour of both unconditional $\beta$ - and $\sigma$-convergence.

\section{[Table 2 around here]}

Based on these results, a researcher following the traditional approach would probably conclude the analysis with a reassuring note: our hypothetical regions are unconditionally converging at an average rate of $2 \%$ and the cross-sectional dispersion is decreasing significantly. Although the speed with which the common steady-state is being approached might appear slow, the general picture that emerges is quite comforting as it describes a process in which all regions are significantly converging towards a common steady state.

But, is this picture an accurate description of what is actually going on? Let us see what the distribution dynamics approach would tell us about the convergence process. Figure 2 shows the stochastic kernel estimated from our hypothetical data on per capita value added expressed in relative with respect to the sample mean. ${ }^{13}$ From the three-dimensional surface plot in the upper part of the figure we can notice the existence of two local maxima in both poor and rich parts of the income range while a sizeable dip appears in the middle-income portion. This

\footnotetext{
12 These statistics are alternative to the $T_{1}$ statistic proposed by Lichtenberg (1994). According to Carree and Klomp (1997), the $T_{1}$ has a large probability of committing a type II error of incorrectly rejecting the convergence hypothesis, especially for short time periods. Consequently, the two authors have proposed the statistics adopted in the present paper. The first statistic, $\mathrm{T}_{2}$, is based on the likelihood ratio, while the second, $\mathrm{T}_{3}$, is derived as an adjusted version of the $\mathrm{T}_{1}$ test statistic.

13 As explained in the Technical Appendix, all stochastic kernel estimates reported in the paper are obtained using Gaussian kernels with variable bandwidths. Data and Matlab codes employed in the analysis are available from the author's web site: http://www.dse.unive.it/ smagrini/it/ricerca/software/software.htm.
} 
features are made even more evident from the percentage ${ }^{14}$ contour plot: both the peaks and the dip in the stochastic kernel lay approximately on the 45-degree diagonal; however, while the density mass that surrounds the two peaks is steeper than the main diagonal, the density mass corresponding to the dip is flatter. This suggests that the middle-income class is vanishing and our hypothetical regions are polarising into low-income and high-income groups.

\section{[Figure 2 around here]}

Figure 3, where the initial (or "1996") distribution is compared to the ergodic, provides unambiguous confirmation of this process: while the former distribution is unimodal, the latter is visibly bimodal, with a deep trough corresponding to the average income. In other words, by magnifying the intra-distributional dynamics through the ergodic distribution we are able to see that our hypothetical regions are subject to a process of divergence that leads them to polarise into two separate clubs.

\section{[Figure 3 around here]}

To sum up, the distribution dynamics approach provides a far less reassuring picture than the one drawn through the regression approach. Based on this example, therefore, the note of scepticism expressed in Section 3 with respect to the informative content of the regression approach clearly appears well founded: giving no information on intra-distribution dynamics, this approach might produce misleading results.

\subsection{Convergence among Italian regions}

In the case of Italy, numerous studies of $\beta$-convergence have been carried out at the NUTS2 (Regioni) level and fewer ones at the NUTS3 (Province) level. In synthesis, most of the existing analyses report evidence of both conditional and unconditional convergence. However, significant variations in the estimated values of the rate of convergence are found depending on the adopted method, on the period under analysis, on the territorial units and, in conditional convergence studies, on the specification. In particular, analyses that apply OLS to per capita income data at the Province level generally find evidence of unconditional convergence - at rates within the usual 1\%-3\% range - up until the mid-1970s and no evidence of unconditional convergence thereafter (Arbia et al., 2005; Arbia et al., 2002; Cosci and Mattesini, 1995; Fabiani and Pellegrini, 1997). According to similar studies at the Region level, unconditional convergence proceeds at the usual rates up to the mid-1970s, it comes to a halt during the 1980s and the beginning of the 1990s and later re-emerges, although at quite a slow pace (Aiello and Scoppa, 2006; Carmeci and Mauro, 2002; Cellini and Scorcu, 1997; Daniele, 2002; Loddo, 2006; Paci and Pigliaru, 1997; Paci and Saba, 1998; Vamvakidis, 2003). In addition, estimated convergence rates tend to be slightly higher in studies of conditional convergence (but with wide variations depending on the chosen set of conditioning variables; see, among others, Cosci and Mattesini, 1995; Daniele, 2002; Fabiani and Pellegrini, 1997; Forni and Paba, 2000) and in studies concentrating on labour productivity rather than on per capita income (Carmeci and Mauro, 2002; Daniele, 2002; Paci and Pigliaru, 1997; Paci and Saba, 1998; Vamvakidis, 2003).

14 The lines reported in all contour plots are percentage contour lines. In particular, the value adjacent to each line indicates the percentage of the density volume above (on the vertical axis of the three-dimensional plot) the line itself. 
As usual, panel data studies generally tend to deliver estimates of the convergence rate that are substantially higher than those obtained from cross-sectional studies. For example, Aiello and Scoppa (2006), using labour productivity at the Region level for the period 1980-2002, find convergence rates between 10 and $22 \%$, depending on the estimator and the specification. Similarly, Carmeci and Mauro (2002) report annual convergence rates in per capita GDP levels across Regions between 12 and 23\% for the period 1963-1995, while Loddo (2006) reports convergence rates around 20\% over the period 1994-2004. An interesting exception is the study by Arbia, Basile and Piras (2005) in which the authors estimate a fixed effects panel data model that allows for spatial autocorrelation effects and report convergence rates across Italian Provinces which are lower than those obtained through OLS specifications. In addition, very few studies have employed time series methods using per capita income data at the Region level. So, for instance, Morgani and Ricciuti (2001) find conditional convergence for the period 1951-1998, absolute convergence in the first subperiod (1951-1973) and divergence in the second (1974-1998) while De Siano and D'Uva (2006) find strong conditional convergence for the period 1981-2003.

Finally, most of the just cited studies have also analysed $\sigma$-convergence. In this case, the pattern that emerges for the Italian Regions is U-shaped, as the measures of dispersion tend to decrease between the beginning of the 1950s and the mid-1970s, remain constant up to mid1980s and then increase up to the beginning of the new century. In contrast, dispersion of per capita GDP at the Province level decreases up to 1970 and then levels off up to the beginning of 1990s.

It is quite evident from this brief account of the literature that virtually all the existing analyses on regional convergence in Italy have concentrated on administratively defined regions. $^{15}$ However, as emphasised elsewhere (Cheshire and Hay, 1989; Cheshire and Magrini, 2000; Magrini, 1999 and 2004), administratively defined regions are likely to misrepresent both the level and the growth rate of per capita income of the underlying economies and thus lead to potentially erroneous results. ${ }^{16}$ Consequently, in this second part of the empirical analysis I will analyse convergence in per capita income not only across a set of administratively defined regions (the Provinces) ${ }^{17}$ but also across a set of functional ones, the Local Labour Systems (Sistemi Locali del Lavoro - LLSs), defined by the National Statistical Institute (ISTAT) ${ }^{18}$ at census rounds on the basis of daily commuting flows. In particular, to ease comparisons, I have concentrated on the Local Labour Systems (based on the 1991 Census of Population) that correspond to the main municipality (Capoluogo di Provincia) of each of the 103 Italian Provinces. Finally, since comparable data on per capita

\footnotetext{
15 The only exception I am aware of is the study by Pellegrini (2002) in which, however, the author analyses convergence in unemployment rates, rather than in per capita income, adopting the distribution dynamics approach.

Since output is measured at workplaces while population at residences, unless the definition of a region has been selected to abstract from commuting patterns, the measured levels of per capita income will be highly misleading. In addition, processes of decentralisation or recentralisation of residences relative to workplaces are likely to affect per capita income growth rates for administratively defined regions. See, references in the text for a detailed discussion.

17 I chose to analyse the Provinces for two reasons. First, they are relatively understudied compared to Regions; second, they can be meaningfully compared to the chosen subset of LLSs.

18 The methodology adopted by ISTAT for partitioning the Italian territory is described in ISTAT (1997).
} 
GVA for the LLSs are available only over the period $1996-2002,{ }^{19}$ the analysis of convergence is limited to this relatively short time period also for the Provinces. ${ }^{20}$

Let us now look at the empirical results about convergence, starting from the Provinces. According to the estimates reported in Table 3, the coefficient of the initial level of per capita GVA is negative and highly statistically significant, implying that the Italian Provinces have experienced a process of unconditional convergence over the 1996-2002 period. In other words, it seems that, analogously to what has been reported in the literature with respect to the Regions, also the convergence process across Italian Provinces has regained some momentum from the second half of the 1990s. More precisely, the Provinces appear to have converged towards a common steady state at an annual rate of about $1.6 \%$. In addition, the two test statistics proposed by Carree and Klomp and reported in Table 4 suggest that the crosssectional variance has decreased in a statistically significant manner. Summing up, according to the regression approach we find unequivocal evidence of both unconditional $\beta$ - and $\sigma$ convergence. However, when we move to the distribution dynamics approach a rather different picture emerges. Similar to what we observed in the simulation exercise, the estimate of the stochastic kernel depicted in Figure 4 shows the existence of two local maxima in both poor and rich parts of the income range and of a sizeable dip in correspondence with average incomes. Also, the density mass surrounding the peaks is steeper than the main diagonal while the density mass corresponding to the dip is somewhat flatter, suggesting that the two peaks act as "basins of attraction" for abutting observations. However, differently from above, the low-income peaks lays clearly underneath the 45-degree diagonal while the rich-income peak is slightly above it. This indicates that the distance between the two peaks exhibited a tendency to decrease over the 1996-2002 period. Disappointingly, this tendency is only partial as we can see from the comparison between the "1996" and the ergodic distributions shown in Figure 5: despite the reduction in crosssectional dispersion characterising the stationary distribution, the two peaks remain visibly separated. Once more, then, the regression approach appears to convey a misleading message: by focussing on the representative economy and overlooking intra-distributional dynamics, it fails to uncover the strong degree of polarisation that continues to exist among the Italian Provinces.

\section{[Tables 3 and 4 around here]}

\section{[Figures 4 and 5 around here]}

Finally, let us turn to the Local Labour Systems. Once more, from Table 5 we find evidence of a statistically significant process of unconditional $\beta$-convergence according to which the LLSs have approached the common steady state at a rate of about $2.3 \%$ per year. Furthermore, Table 6 shows that the cross-sectional distribution of per capita GVA has witnessed a significant decrease in dispersion around the mean. Hence, as it was the case of

\footnotetext{
19 For LLSs, data for years before 1996 are based on a different accounting system (ESA79 rather than ESA95) while data for 2002 and 2003 refer to the newer set of LLSs (as defined on the basis of the 2001 Census of Population).

${ }_{20}$ The basic data source is the National Statistical Institute (ISTAT). In particular, data on population as well as on Gross Value Added (basic prices, ESA95) at current prices for both Local Labour Systems and Provinces have been downloaded from the Institute's web site. Data on Gross Value Added have then been deflated using the Gross Value Added (basic prices, ESA95) deflator published by the Bank of Italy (Banca d'Italia).
} 
the Provinces, also the Local Labour Systems appear to have been subject to both unconditional $\beta$ - and $\sigma$-convergence over the 1996-2002 period.

\section{[Tables 5 and 6 around here]}

However, the major difference with what we have seen before is that now the results from the application of the distribution approach appear to confirm those obtained through the regression approach. While two major peaks are still detectable from Figure 6, it must be noted that the one that corresponds to low income regions lays well underneath the 45-degree diagonal while the peak corresponding to middle-income regions lays above the 45-degree diagonal; in addition, the entire density mass shows a explicit rotation in a counter-clockwise direction. All this is indicative of a process of convergence among the LLSs which is then confirmed by Figure 7, showing that the ergodic distribution is clearly unimodal and characterised by a lower degree of dispersion than the "1996" one.

\section{[Figures 6 and 7 around here]}

\section{Conclusions}

This paper has provided an overview of the two most commonly adopted approaches to the empirical analysis of economic convergence.

The main point I have made over the presentation is that convergence findings obtained through the regression approach might be misleading. The traditional tool, $\beta$-convergence, concentrates on the behaviour of a representative economy and is thus unable to reveal the dynamics of the entire cross-sectional distribution. But even resorting to the concept of $\sigma$ convergence does not allow to fill this informational gap: a constant, or even decreasing, cross-sectional variance is fully consistent with the concentration of the economies into two (polarisation) or more (stratification) separate convergence clubs.

Then, I have provided a few examples to substantiate such statement. In the opening example, after generating two hypothetical cross-sectional series able to produce $\beta$ - and $\sigma$-convergence as well as polarization dynamics, I have shown that the regression approach, while obviously able to detect $\beta$ - and $\sigma$-convergence, fails to uncover the tendency towards the formation of two distinct convergence clubs. In other words, incipient polarisation dynamics are hidden to the traditional method of empirical analysis. In contrast, these dynamics are unambiguously revealed through the distribution dynamics analysis.

One may object that the convergence dynamics produced by these two series are clearly ad $h o c$, with the obvious intent of generating an unnecessarily difficult test ground for the regression approach. Yet, the use of data on per capita GVA for two sets of Italian regions confirmed that the uninformative and potentially misleading representation of the convergence process provided by the regression approach is not just a purely theoretical possibility. Indeed, we have seen that a strong degree of polarisation continues to exist among the Italian Provinces, despite that they have been subject to a parallel process of unconditional $\beta$ - and $\sigma$-convergence. It was only when we focussed on a set of functionally defined regions, 
the Local Labour Systems, that the results obtained from the two empirical approaches appeared to come to an agreement, both describing a process of extensive convergence.

In passing, the analysis presented in the second part of the empirical section served another purpose: it allowed to show how alternative criteria for subdividing national territories may lead to conflicting results. In particular, starting from the opinion that administratively defined regions are likely to misrepresent the level and the growth rate of per capita income, the strongly conflicting convergence dynamics characterising the two alternative sets of regions suggest that the use of inappropriately defined regions could lead to misleading conclusions.

\section{Acknowledgements}

I am grateful to Margherita Gerolimetto for very valuable comments on some technical aspects of the paper and to Georgios Fotopoulos for insightful discussions on estimation issues in Matlab. Needless to say, I remain solely responsible for any errors or omissions. 


\section{Technical Appendix - Stochastic kernel estimation via kernel density estimators}

As explained in the text, our goal is to get an estimate of the conditional probability density function

$$
f_{x(t+s) \mid x(t)}=\frac{f_{x(t), x(t+s)}}{f_{x(t)}}
$$

In turn, this requires an estimate of the joint probability density function of $x(t)$ and $x(t+s)$ and an estimate of the probability density function of $x(t)$. To obtain the former I make use of a bivariate kernel density estimator. The latter is then obtained by numerically integrating the estimate of the joint density. ${ }^{21}$

To describe how the joint probability density function is estimated, we must first introduce some notation. So, let us consider a 2-dimensional random vector

$$
\mathbf{x}=(x(t), x(t+s))^{\prime}, \quad \text { with } \mathbf{x} \in \mathrm{P}^{2},
$$

where $x(t)$ and $x(t+s)$ are 1-dimensional random variables. Within this setting, draw a random sample of size $n$ so that there are $n$ observations for each of the two random variables. Clearly, these two vectors of $n$ observations each are the data given to the researcher. Then, collect the $i$-th observation of each of the variables in the vector

$$
\mathbf{x}_{i}=\left(x_{i}(t), x_{i}(t+s)\right)^{\prime}, \quad \text { with } i=1, \ldots, n .
$$

We can now turn to the estimation procedure. The general form of the kernel estimator of $f_{x(t), x(t+s)}$ is

$$
\hat{f}_{x(t), x(t+s)} \equiv \hat{f}_{\mathbf{x}}=\frac{1}{n|\mathbf{H}|} \sum_{i=1}^{n} K\left(\mathbf{H}^{-1}\left(\mathbf{x}-\mathbf{x}_{i}\right)\right)
$$

where $K: \mathrm{P}^{2} \rightarrow \mathrm{P}_{+}$is a bivariate kernel function satisfying

$$
\int_{i}{ }^{2} K(\mathbf{x}) d \mathbf{x}=1
$$

while $\mathbf{H}$ is a symmetric and positive definite $2 \times 2$ matrix known as the bandwidth matrix.

In general, the quality of the density estimate depends on characteristics of the kernel function and of the bandwidth matrix. However, it is now well established in the literature that the kernel estimator is not very sensitive to the choice of $K$ (Silverman, 1986; Wand and Jones, 1995). Consequently, I take $K$ to be the bivariate Gaussian kernel function

$$
K(\mathbf{x})=\frac{1}{2 \pi} e^{-\frac{1}{2} \mathbf{x}^{\prime} \mathbf{x}}
$$

In contrast, the choice of the bandwidth matrix is quite crucial. To see why, we must evaluate the performance of the kernel density estimator using some global error criterion. A common choice for such a criterion is the Mean Integrated Squared Error (MISE) between the actual density and the estimate

$$
\operatorname{MISE}=E \int_{i^{2}}\left[\hat{f}_{\mathbf{x}}-f_{\mathbf{x}}\right]^{2} d \mathbf{x}
$$

\footnotetext{
$21 \quad$ Alternatively, the marginal distribution can be estimated directly using a univariate kernel density estimator. However, as pointed out by Overman and Ioannides (2001), the two estimators have identical asymptotic statistical properties and produce very similar results in practice.
} 
Since the MISE is not mathematically tractable (except in special cases), it is customary to resort to its asymptotic approximation via the first two terms of a Taylor's series expansion, know as the AMISE. Before proceeding, it is convenient to write $\mathbf{H}=h \mathbf{A}$, where $h$ is a positive scalar and $\mathbf{A}$ is a $2 \times 2$ matrix that satisfies $|\mathbf{A}|=1$. Then, it is possible to show (Scott, 1992; Wand and Jones, 1995) that the AMISE of the kernel estimator is

$$
\text { AMISE }=\frac{1}{n h^{2}} R(K)+\frac{h^{4}}{4} \int_{i^{2}}\left\{\operatorname{trace}\left[\mathbf{A A}^{\prime} \nabla^{2} f_{\mathbf{x}}\right]\right\}^{2} d \mathbf{x}
$$

where $R(K)=\int_{{ }^{2}} K(\mathbf{x})^{2} d \mathbf{x}$ is a measure of the roughness of the kernel function $K$ while $\nabla^{2} f_{\mathbf{x}}$ is the $2 \times 2$ Hessian (matrix of second partial derivatives) of $f_{\mathbf{x}}$.

Through the AMISE we can appreciate how the performance of the estimator depends on the bandwidth. The first term in equation (A.2) is the integrated variance, which is proportional to $(n h)^{-1}$, while the second term is the integrated squared bias, which is proportional to $h^{4}$. This leads to the well known bias-variance trade-off: a too small $h$ will increase the variance of the estimate (thus leading to a tendency for spurious features to appear in the estimate) while a too large $h$ will increase the bias (and essential details of the distribution are likely to be sacrificed).

Based on the above discussion, therefore, the choice of the bandwidth matrix generally tries to find a global compromise between variance and bias. To do this, it is first of all necessary to select a form for the bandwidth matrix. There are three main classes for parametrizing the bandwidth matrix which consequently imply a different number of bandwidths (Wand and Jones, 1993). In the first class, only one bandwidth is needed as the same amount of smoothing is applied in all dimensions and the bandwidth matrix simplifies to $\mathbf{H}=h \mathbf{I}$. The second class, commonly referred to as the product kernel estimator, requires the estimation of two bandwidths, each determining the amount of smoothing in the corresponding dimension, and the bandwidth matrix becomes diagonal: $\mathbf{H}=\operatorname{diag}\left(h_{x}, h_{y}\right)$. The last class employs a full smoothing matrix and requires the estimation of three bandwidths.

According to Wand and Jones (1993), who have investigated the relative merits of the three parametrizations in the bivariate setting, the adoption of a diagonal bandwidth matrix is an adequate choice in many situations while, in other cases, a full matrix is more appropriate. In practice, however, given the complexities involved in the full matrix case, the bandwidth matrix is very often restricted to a class of positive definite diagonal matrices. In the analysis, I follow this practice and hence concentrate on the product kernel. As a result, the kernel estimator in (A.1) simplifies to

$$
\hat{f}_{\mathbf{x}}=\frac{1}{n h_{x(t)} h_{x(t+s)}} \sum_{i=1}^{n} K\left(\frac{x(t)-x_{i}(t)}{h_{x(t)}}, \frac{x(t+s)-x_{i}(t+s)}{h_{x(t+s)}}\right)
$$

or, when the kernel function is the bivariate Gaussian defined above, to

$$
\hat{f}_{\mathbf{x}}=\frac{1}{n} \sum_{i=1}^{n}\left[\frac{1}{\sqrt{2 \pi} h_{x(t)}} e^{-\frac{1}{2}\left(\frac{x(t)-x_{i}(t)}{h_{x(t)}}\right)^{2}} \frac{1}{\sqrt{2 \pi} h_{x(t+s)}} e^{-\frac{1}{2}\left(\frac{x(t+s)-x_{i}(t+s)}{h_{x(t+s)}}\right)^{2}}\right]
$$


Clearly, the bivariate product kernel in Equation (A.3) consists of the product of two onedimensional kernels, each estimated using a specific, and fixed, bandwidth. These two bandwidths are then usually estimated from the data using some optimal bandwidth selection algorithm. ${ }^{22}$ However, it is also clear from the previous equation that, while different amount of smoothing is applied across dimensions, the same amount of smoothing is applied along each dimension. So, looking separately at each dimension, the bias-variance trade-off issue comes out again: particularly when the marginal density functions are multimodal or longtailed, using a fixed bandwidth along each dimension might lead to poor results as the bandwidths tend to be too narrow in areas with only sparse observations (thus returning an undersmoothed estimate of this part of the density and increasing the variance) and too wide in others (thus leading to an oversmoothed estimate and to an increase in the bias). In such instances, a possible solution is to resort to a variable bandwidth, i.e. a bandwidth that varies along each dimension of the sample data, being wider where observations are sparser and narrower where observations are denser. ${ }^{23}$ Clearly, the use of a variable bandwidth should also reduce the effect of outliers in the kernel density estimate. ${ }^{24}$

In general, there are two main classes of variable bandwidth selectors (Sain and Scott, 1996). In the balloon estimator, introduced by Loftsgaarden and Quesenberry (1965) as the $k$-th nearest-neighbour estimator, the bandwidth varies at each estimation point; in contrast, in the sample-point estimator introduced by Breiman et al. (1977), the bandwidth varies at each data point. As for their relative merits, one clear advantage of the sample-point estimator is that it will always integrate to 1 so that the estimates are true density functions. Moreover, the balloon estimator has been shown to suffer severe bias problem, particularly in the tails, in the univariate and bivariate settings. (Silverman, 1986; Terrell and Scott, 1992). Because of this, I will concentrate our attention on the sample point estimator.

Given the choice to adopt a diagonal bandwidth matrix - and hence to use a product kernel - I simplify the computation of the variable bandwidths by concentrating on one dimension at a time. So, let us start from the variable $x(t)$. Intuitively, it follows from the general motivation to the variable bandwidth that this should be obtained, at each data point, by rescaling the fixed bandwidth $h_{x(t)}$ by a factor that is inversely related to the density at that point

$$
h_{x(t)_{i}} \propto f_{x(t)}^{-\alpha} \text {. }
$$

In particular, Abramson (1982a) proposed to use $\alpha=1 / 2$, showing that this leads to bias reduction compared to the fixed bandwidth estimate. Moreover, while the density $f_{x(t)}$ in (A.4) is obviously unknown, Abramson (1982b) proves that using a non-adaptive pilot estimate for $f$ is adequate. In practice, this means that the vector of $n$ variable bandwidths for $x(t)$ can be obtained through a 4-step strategy:

1. estimate the fixed bandwidth $h_{x(t)}$ from the data using some optimal bandwidth selection algorithm;

\footnotetext{
22 In the light of the discussion on the bias-variance trade-off, optimal values for the bandwidths can be derived by seeking a compromise between variance and bias that minimises one of the measures of the estimation error, say the AMISE. Given that the AMISE is not known, as it depends on the unknown density $f$, an optimal bandwidth selection algorithm firstly produces an estimate of AMISE from the data and then finds its minimiser. Available algorithms for diagonal matrices include plug-in (Wand and Jones, 1994) and biased crossvalidation (Sain et al., 1994) selectors.

${ }_{23}$ An adaptive kernel method for estimating the stochastic kernel is also used by Johnson (2000 and 2005).

Again, see Basile (2007) for an alternative approach to the problem.
} 
2. through the fixed bandwidth, obtain a pilot kernel density estimate $f_{x(t)}^{0}$;

3. calculate a set of local adjustment parameters

$$
\lambda_{x(t)_{i}}=\left(\frac{f_{x(t)_{i}}}{g_{x(t)}}\right)^{-\alpha} \quad \text { with } i=1, \ldots, n
$$

where $g_{x(t)}$ is the geometric mean of the pilot estimates $f_{x(t)_{i}}^{9}$ at all data points and $\alpha$ is a sensitivity parameter such that $0 \leq \alpha \leq 1$;

4. calculate the local bandwidths $h_{x(t)_{i}}=\lambda_{i} h_{x(t)}$, with $i=1, \ldots, n$.

Obviously, this same procedure can then be applied to the variable $x(t+s)$ thus obtaining the second set of $n$ local bandwidths $h_{x(t+s)_{i}}$.

Using these local bandwidths, the bivariate kernel estimator employed in the analysis to estimate the joint probability density function of $x(t)$ and $x(t+s)$ becomes

$$
\hat{f}_{\mathbf{x}}=\frac{1}{n} \sum_{i=1}^{n}\left\{\frac{1}{h_{x_{i}(t)}} K\left(\frac{x(t)-x_{i}(t)}{h_{x_{i}(t)}}\right) \frac{1}{h_{x_{i}(t+s)}} K\left(\frac{x(t+s)-x_{i}(t+s)}{h_{x_{i}(t+s)}}\right)\right\}
$$

In particular, in all the estimates reported in the paper, I have used a bivariate plug-in selector (Wand and Jones, 1994) to get the fixed bandwidths $h_{x(t)}$ and $h_{x(t+s)}$ for the pilot estimates, and followed Abramson's "square-root" law, i.e. posing $\alpha=1 / 2$, to calculate the local adjustment parameters. $^{25}$

Finally, as explained at the outset, the estimate of the stochastic kernel is obtained by dividing the estimated joint density of $x(t)$ and $x(t+s)$ by an estimate of the marginal density of $x(t)$; the latter, in turn, is calculated by numerically integrating the estimate of the joint density over $x(t+s)$. The ergodic density is then found as the solution to

$$
f_{x(\infty)}=\int_{-\infty}^{\infty} f_{x(t+s) \mid x(t)} f_{x(\infty)} d x
$$

following the approach developed by Johnson (2000 and 2005) and summarised in Fotopoulos (2006). ${ }^{26}$

\footnotetext{
25 Note that for $\alpha=0$, the local adjustment parameters become equal to 1 at all data points and the estimator in (A.5) simplifies into the estimator in (A.3).

${ }_{26}$ As pointed out by Fotopoulos (2006), the published version of Johnson's papers do not include the appendix with the solution's details. However, a document explaining how the ergodic density is computed can be downloaded from Johnson's web site (http://irving.vassar.edu/faculty/pj/pj.htm).
} 


\section{Figures}

Figure 1 Transition paths in the traditional neoclassical model of growth

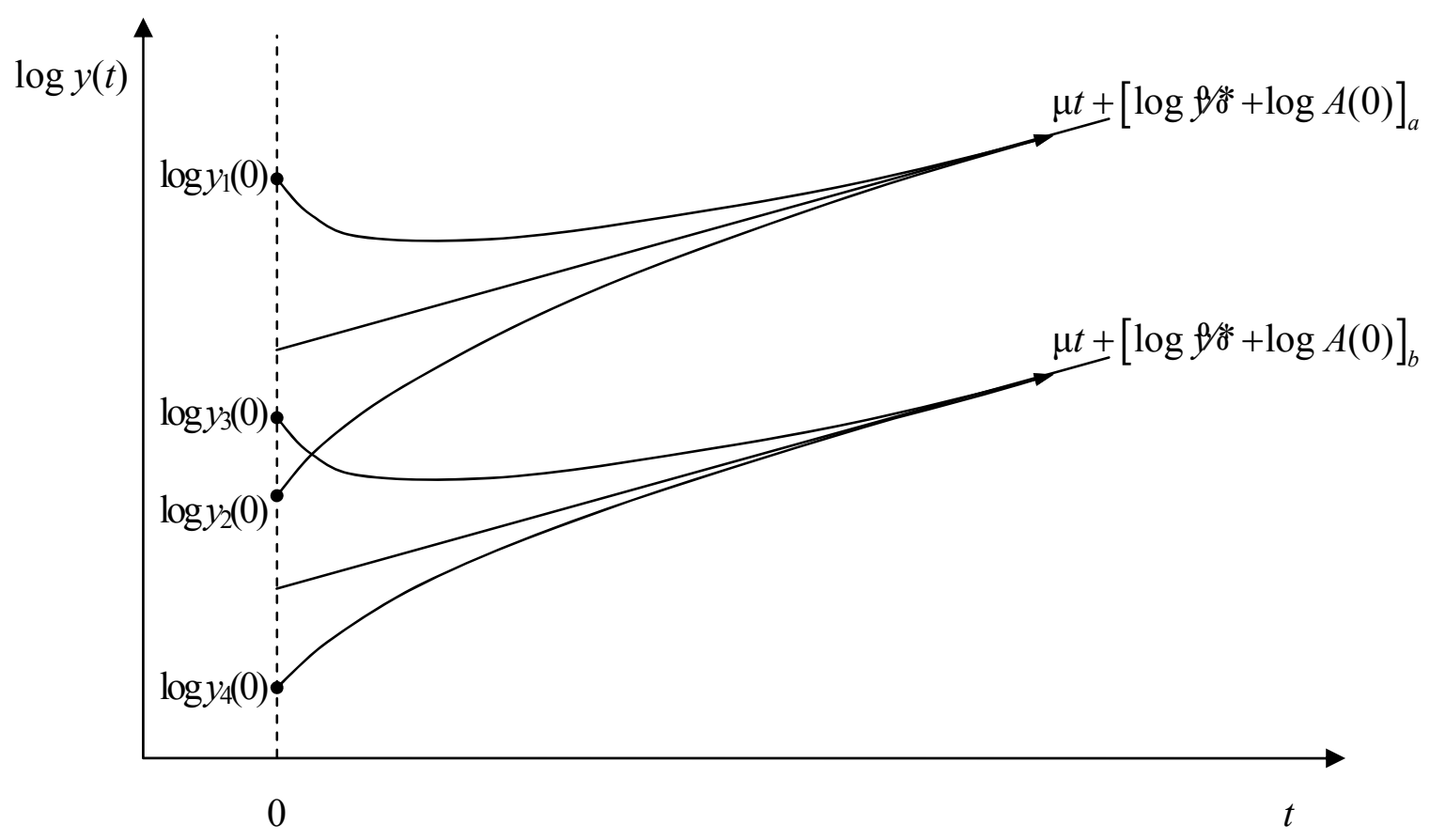


Figure $2 \quad$ Stochastic kernel - Example

a. $3 \mathrm{D}$ surface plot

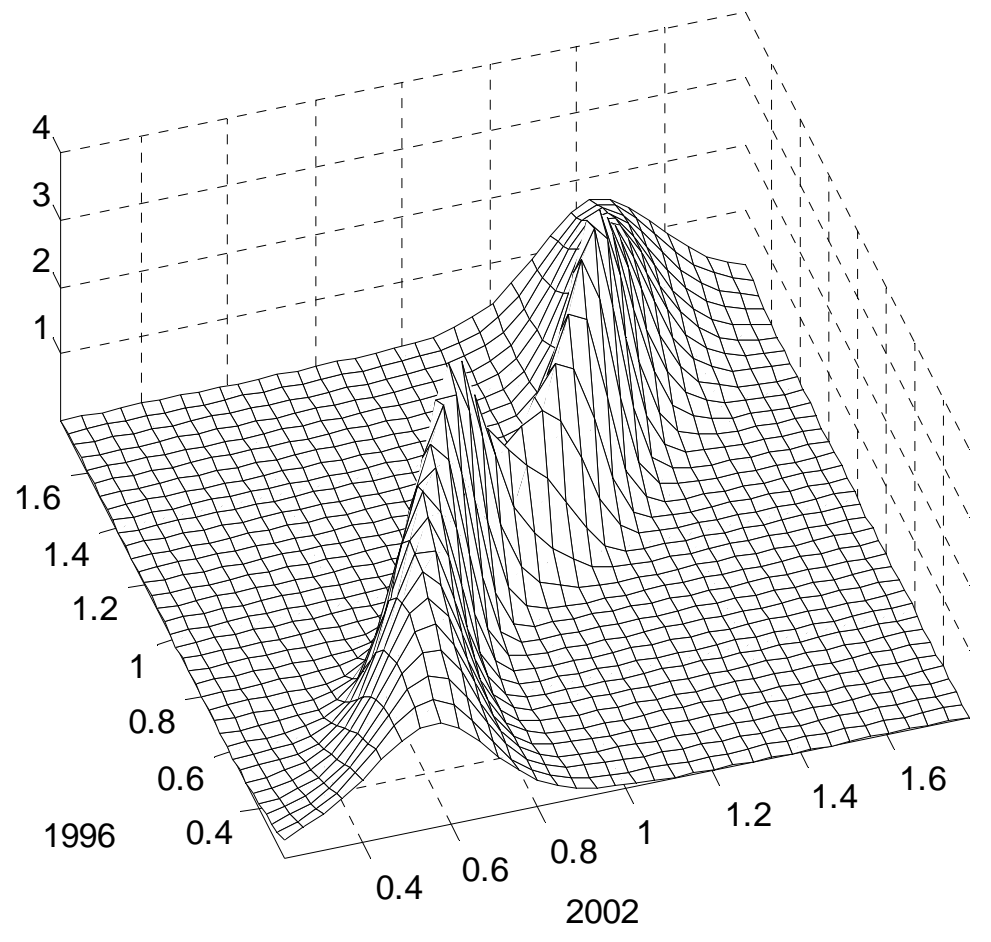

b. percentage contour plot

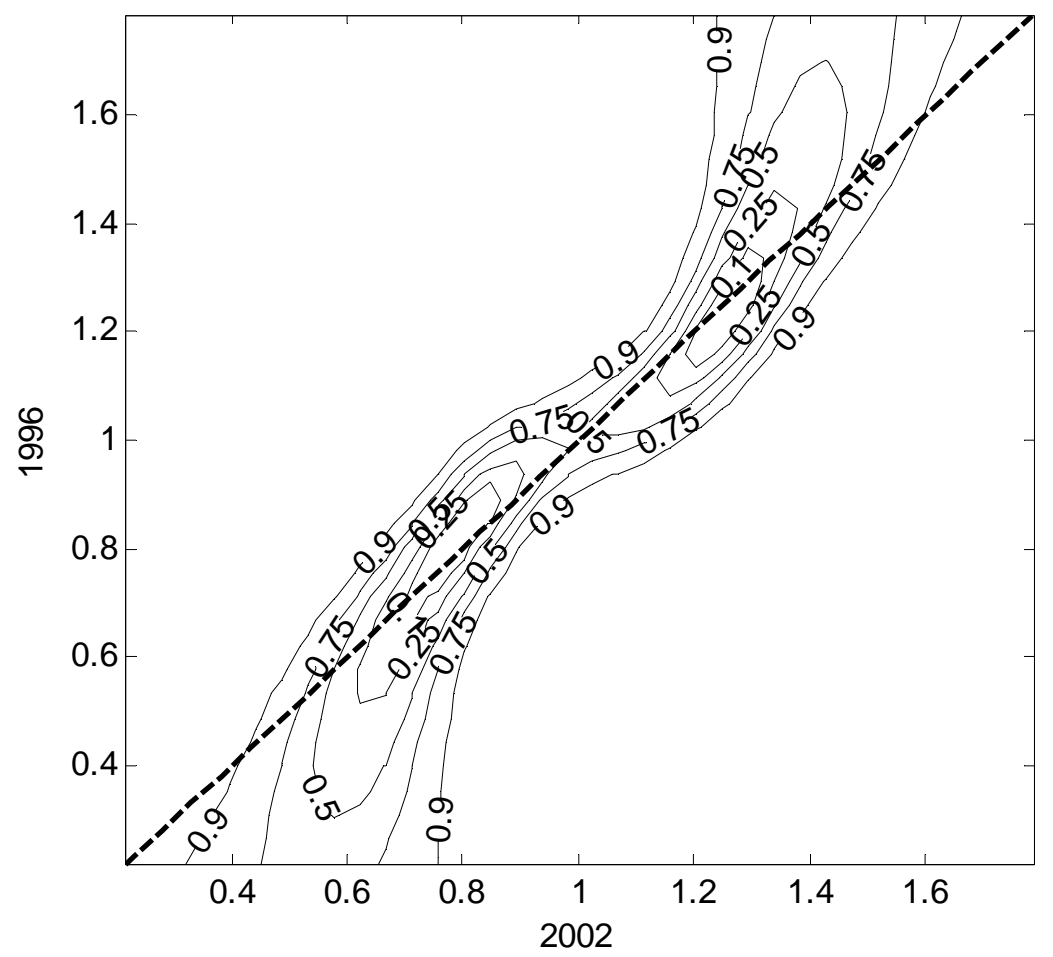

Notes: Estimates use a Gaussian kernel with an adaptive bandwidth 
Figure 3 Distributions - Example initial and ergodic distributions

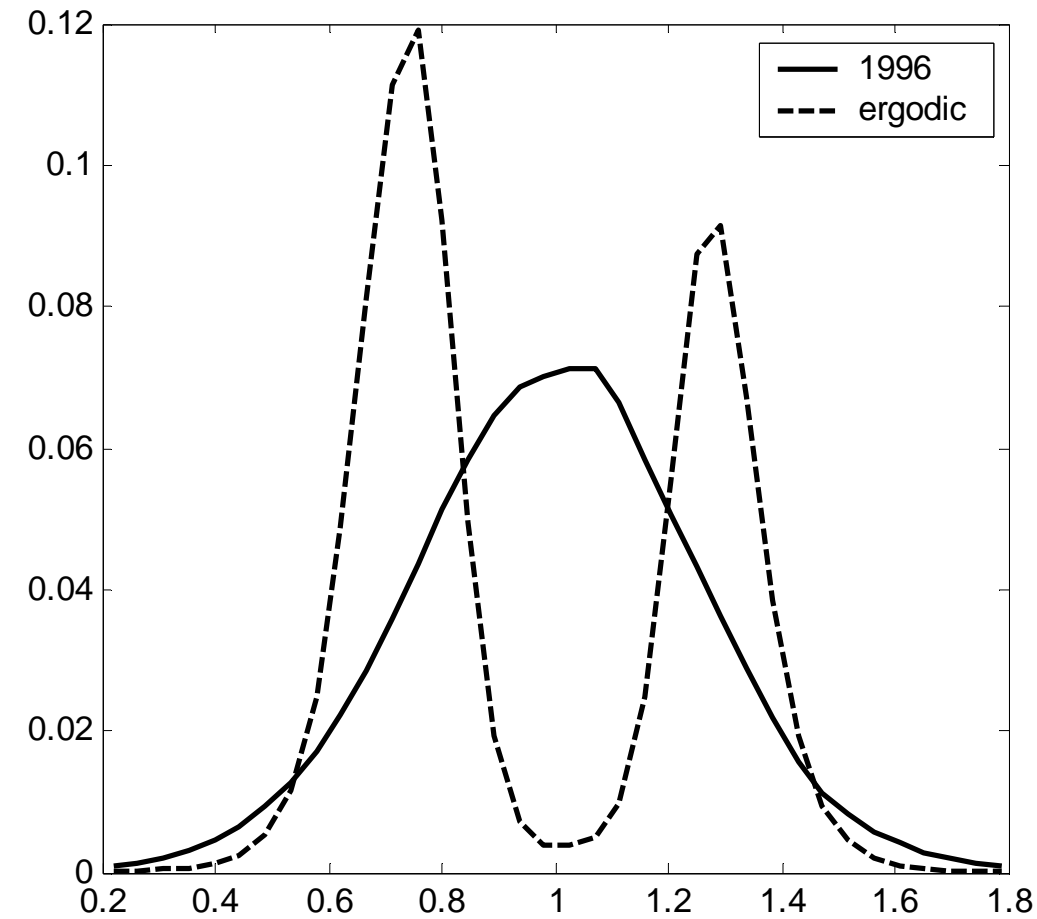

Notes: $\quad$ Estimates use a Gaussian kernel with an adaptive bandwidth 
Figure 4 Stochastic kernel - Provinces

a. 3D surface plot (1996 - 2002)

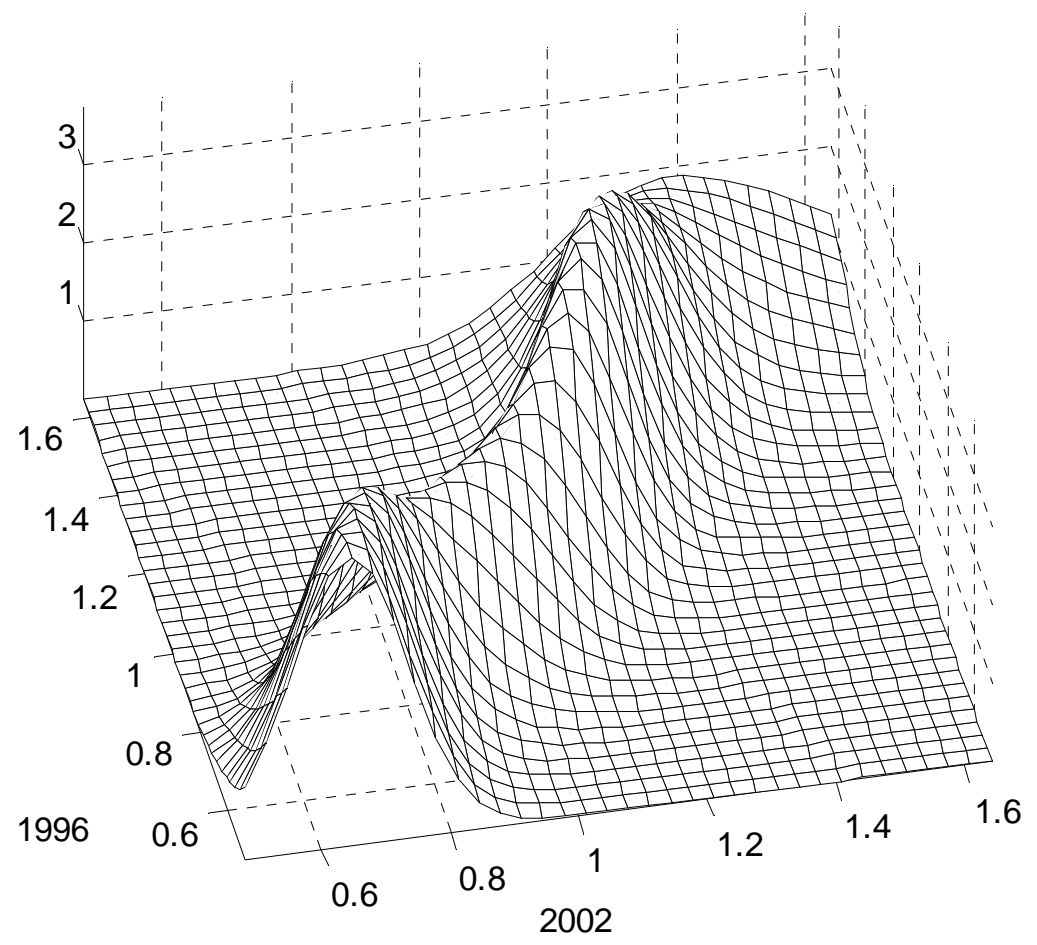

b. percentage contour plot (1996 - 2002)

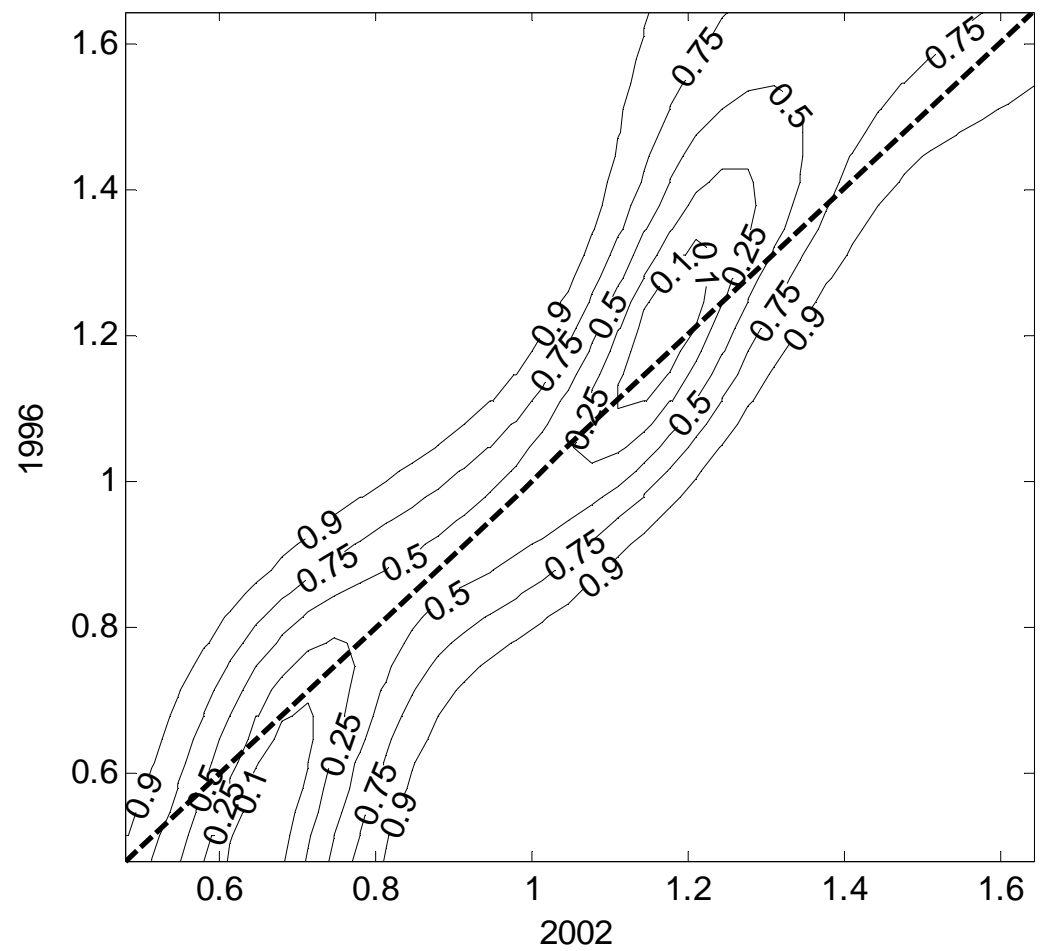

Notes: Estimates use a Gaussian kernel with an adaptive bandwidth 
Figure 5 Ergodic Distribution - Provinces

1996 and ergodic

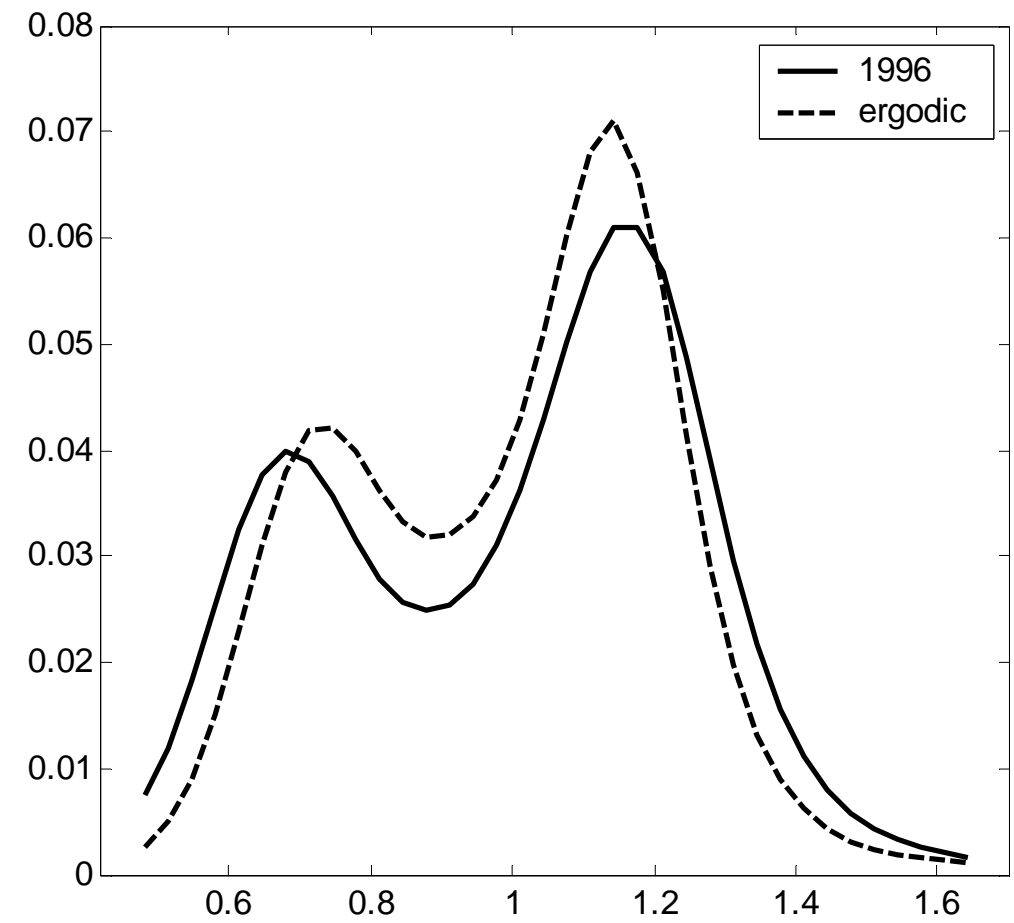

Notes: Estimates use a Gaussian kernel with an adaptive bandwidth 
Figure 6 Stochastic kernel - Local Labour Systems

a. 3D surface plot (1996 - 2002)

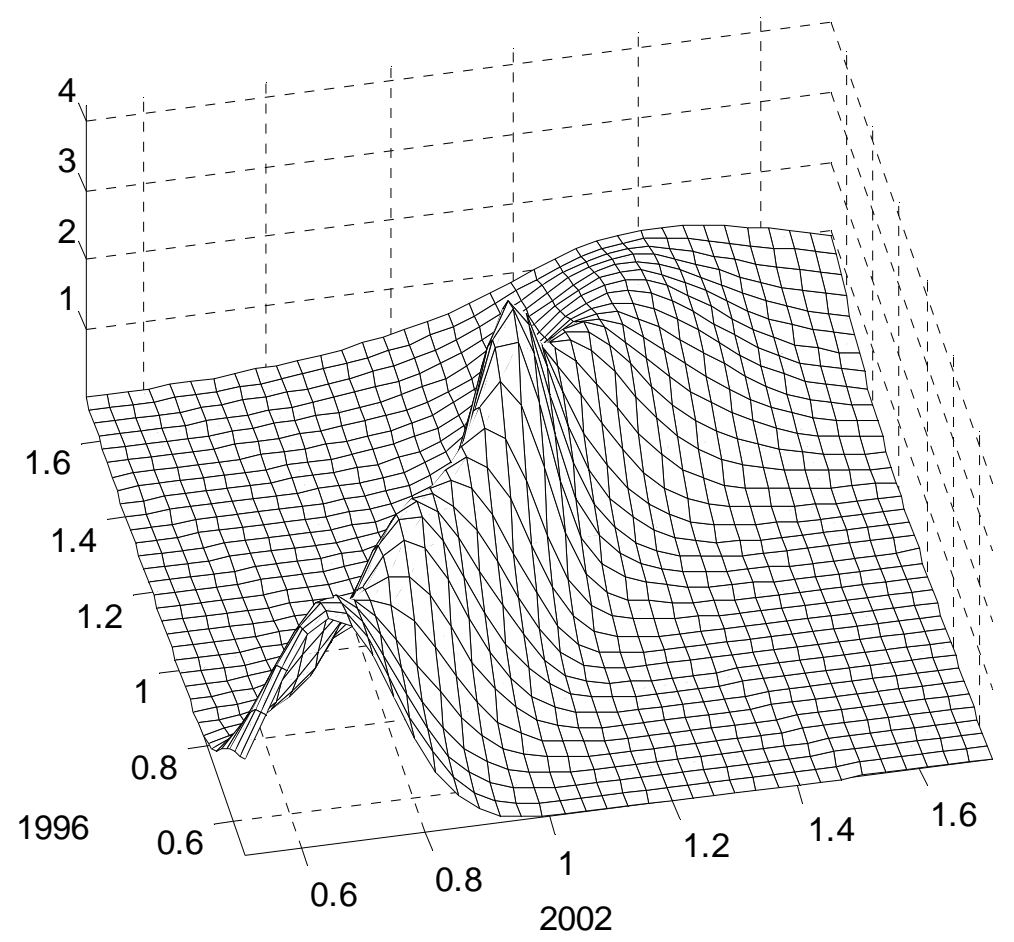

b. percentage contour plot (1996 - 2002)

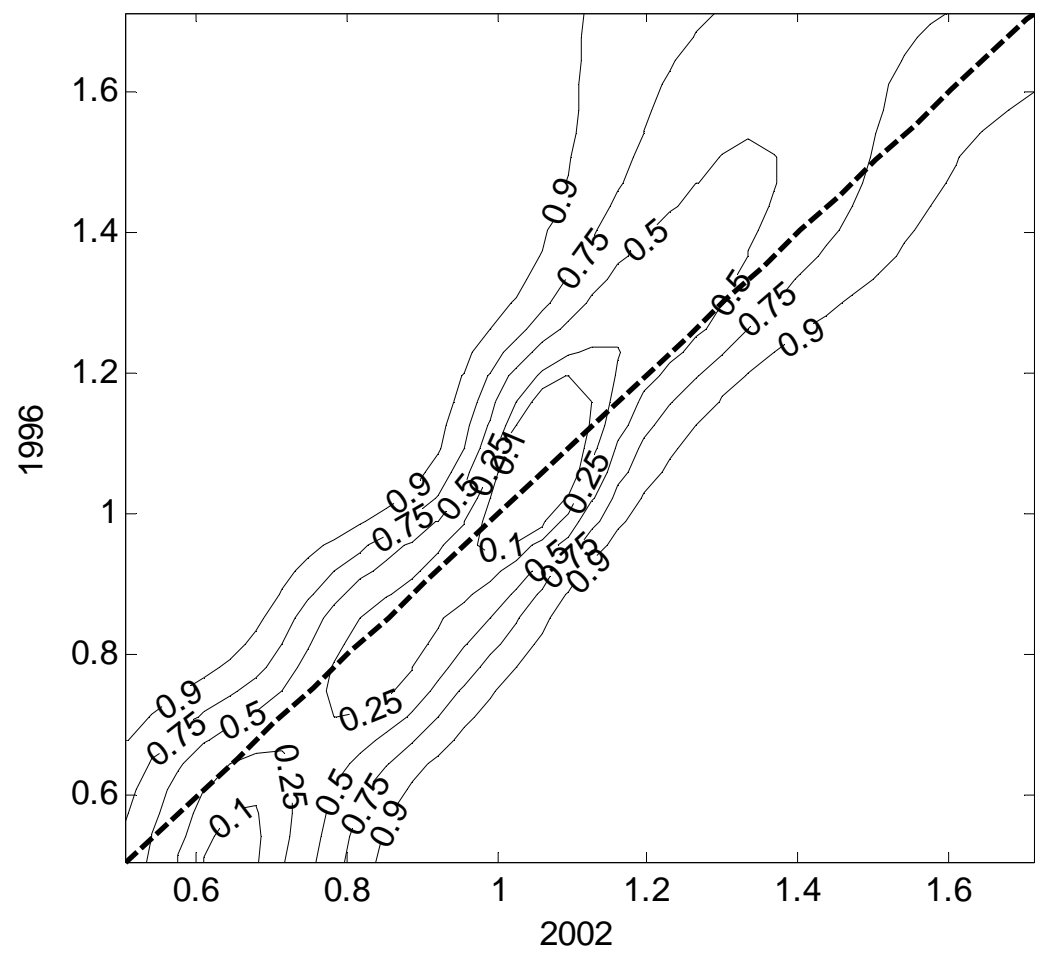

Notes: Estimates use a Gaussian kernel with an adaptive bandwidth 
Figure 7 Ergodic Distribution - Local Labour Systems 1996 and ergodic

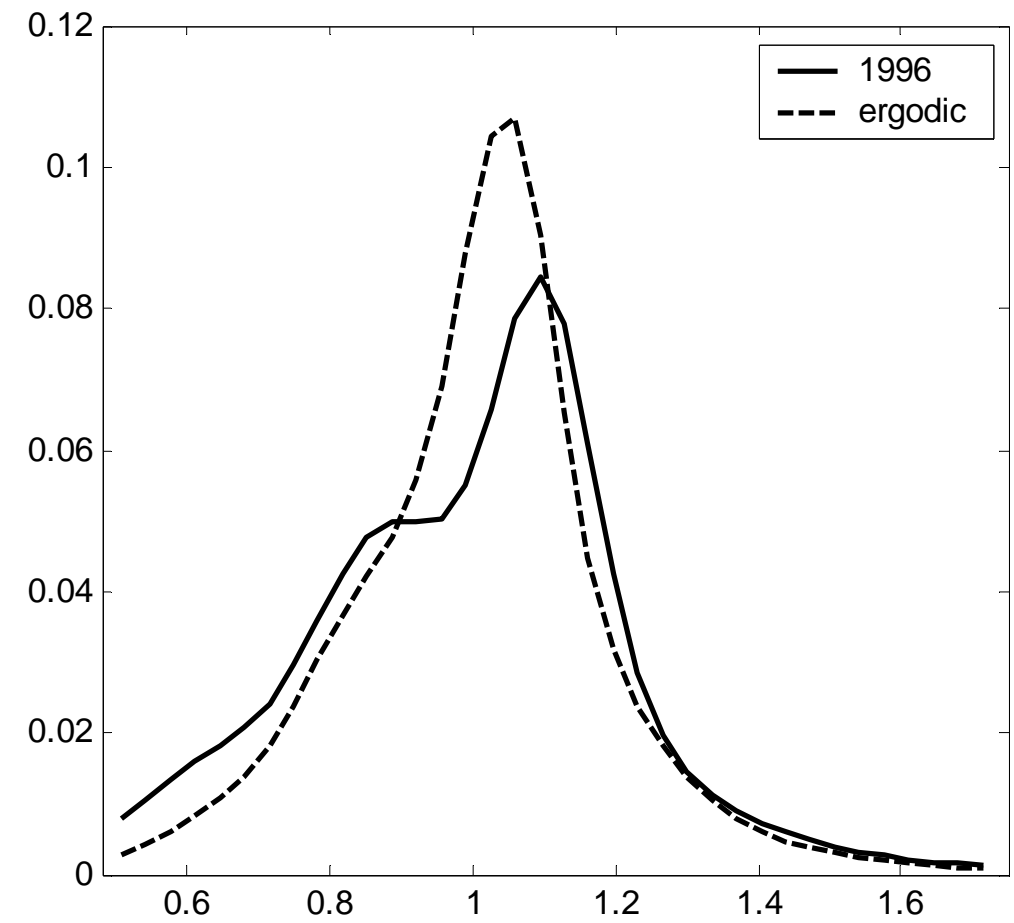

Notes: Estimates use a Gaussian kernel with an adaptive bandwidth 


\section{Tables}

Table $1 \quad \beta$-convergence (Example)

$\begin{array}{lccc}\text { variable } & \text { coefficient } & \text { t-statistic } & \text { p-value } \\ \text { constant } & 0.198093 & 17.1008 & 0.0000 \\ \log \left(\mathrm{y}_{0}\right) / \mathrm{T} & -0.113332 & -15.6153 & 0.0000 \\ \text { speed of convergence }(\beta) & 0.0200 & & \\ \text { half-life (periods) } & 34.5754 & & \end{array}$

Notes: $\quad$ Estimates use $(1 / \mathrm{T}) \log \left(\mathrm{y}_{\mathrm{T}} / \mathrm{y}_{0}\right)$ as dependent variable and assume $\mathrm{T}=6$

$\mathrm{R}^{2}=0.1964 ;$ adj- $\mathrm{R}^{2}=0.1955$

$\beta$ is estimated directly via Nonlinear Least Squares (Gauss Newton method)

The half-life is calculated according to the formula half-life $=(\log 2) / \beta$

Table $2 \quad \sigma$-convergence (Example)

\begin{tabular}{cccccccr}
\multicolumn{2}{c}{ standard deviation } & \multicolumn{2}{c}{ variation coefficient } & \multicolumn{2}{c}{$\mathbf{T}_{2}$ test } & \multicolumn{2}{c}{$\mathbf{T}_{3}$ test } \\
1996 & 2002 & 1996 & 2002 & statistic & p-value & statistic & p-value \\
0.2784 & 0.2550 & 0.0291 & 0.0264 & 116.29 & 0.0000 & 6.67 & 0.0000
\end{tabular}

Notes: $\quad \mathrm{T}_{2}$ : $\mathrm{H} 0=$ no convergence; asymptotically distributed as a $\chi^{2}(1)$

$\mathrm{T}_{3}: \mathrm{H} 0=$ no convergence; asymptotically distributed as a $\mathrm{N}(0,1)$

Table $3 \quad \beta$-convergence (Provinces)

$\begin{array}{lccc}\text { variable } & \text { coefficient } & \text { t-statistic } & \text { p-value } \\ \text { constant } & 0.167084 & 7.8715 & 0.0000 \\ \log \left(\mathrm{y}_{0}\right) / \mathrm{T} & -0.093894 & -7.0601 & 0.0000 \\ \text { speed of convergence }(\beta) & 0.0164 & & \\ \text { half-life (periods) } & 42.1798 & & \\ \end{array}$

Notes: $\quad$ Estimates use $(1 / \mathrm{T}) \log \left(\mathrm{y}_{\mathrm{T}} / \mathrm{y}_{0}\right)$ as dependent variable

$\mathrm{R}^{2}=0.3304$; adj- $\mathrm{R}^{2}=0.3238$

$\beta$ is estimated directly via Nonlinear Least Squares (Gauss Newton method)

The half-life is calculated according to the formula half-life $=\ln (2) / \beta$

Table $4 \quad \sigma$-convergence (Provinces)

\begin{tabular}{cccccccr}
\multicolumn{2}{c}{ standard deviation } & \multicolumn{2}{c}{ variation coefficient } & \multicolumn{2}{c}{$\mathbf{T}_{2}$ test } & \multicolumn{2}{c}{$\mathbf{T}_{3}$ test } \\
1996 & 2002 & 1996 & 2002 & statistic & p-value & statistic & p-value \\
0.2784 & 0.2550 & 0.0291 & 0.0264 & 31.14 & 0.0000 & 2.30 & 0.0106
\end{tabular}

Notes: $\quad \mathrm{T}_{2}$ : $\mathrm{H} 0=$ no convergence; asymptotically distributed as a $\chi^{2}(1)$

$\mathrm{T}_{3}: \mathrm{H} 0=$ no convergence; asymptotically distributed as a $\mathrm{N}(0,1)$ 
Table $5 \quad \beta$-convergence (Local Labour Systems)

\begin{tabular}{lccc} 
variable & coefficient & t-statistic & p-value \\
constant & 0.223892 & 5.5921 & 0.0000 \\
$\log \left(\mathrm{y}_{0}\right) / \mathrm{T}$ & -0.128227 & -5.2066 & 0.0000 \\
speed of convergence $(\beta)$ & 0.0229 & & \\
half-life (periods) & 30.3068 & & \\
\hline
\end{tabular}

Notes: $\quad$ Estimates use $(1 / \mathrm{T}) \log \left(\mathrm{y}_{\mathrm{T}} / \mathrm{y}_{0}\right)$ as dependent variable $\mathrm{R}^{2}=0.2116 ;$ adj- $\mathrm{R}^{2}=0.2038$

$\beta$ is estimated directly via Nonlinear Least Squares (Gauss Newton method) The half-life is calculated according to the formula half-life $=\ln (2) / \beta$

Table $6 \quad \sigma$-convergence (Local Labour Systems)

\begin{tabular}{cccccccc}
\multicolumn{2}{c}{ standard deviation } & \multicolumn{2}{c}{ variation coefficient } & \multicolumn{2}{c}{$\mathbf{T}_{2}$ test } & \multicolumn{2}{c}{$\mathbf{T}_{3}$ test } \\
1996 & 2002 & 1996 & 2002 & statistic & p-value & statistic & p-value \\
0.2311 & 0.2094 & 0.0237 & 0.0213 & 12.32 & 0.0004 & 2.25 & 0.0121
\end{tabular}

Notes: $\quad \mathrm{T}_{2}: \mathrm{H} 0=$ no convergence; asymptotically distributed as a $\chi^{2}(1)$ 


\section{References}

Abramovitz, M. (1986), "Catching Up, Forging Ahead, and Falling Behind", Journal of Economic History, 46 (2): 385-406.

Abramson, I.S. (1982a), "On bandwidth Variation in Kernel Estimates-A Square Root Law", The Annals of Statistics 10 (4): 1217-1223.

Abramson, I.S. (1982b), "Arbitrariness of the Pilot Estimator in Adaptive Kernel Methods", Journal of Multivariate Analysis, 12 (4): 562-567.

Abreu, M., de Groot, H.L.F. and Florax, R.J.G.M. (2005a), "Space and Growth: A Survey of Empirical Evidence and Methods", Région and Développement, 21: 13-44.

Abreu, M., de Groot, H.L.F. and Florax, R.J.G.M. (2005b), "A Meta-analysis of $\beta$ Convergence: The Legendary 2\%”, Journal of Economic Surveys, 19 (3): 389-420.

Aghion, P. and Howitt, P. (1992), "A Model of growth Through Creative Destruction", Econometrica, 60 (2): 323-351.

Aiello, F. and Scoppa, V. (2006), "Convergence and Regional Productivity Divide in Italy: Evidence from Panel Data". In Impresa, Mercato, Lealtà Territoriale, XXVII Conference of the Italian Association of Regional Science (AISRe) Papers and Proceedings, Pisa, October 12-14, 2006.

Anselin, L. (1988), Spatial Econometrics: Methods and Models, London: Kluwer.

Anselin, L. (1995), "Local Indicators of Spatial Association - LISA", Geographical Analysis, 27 (2): 93-115.

Anselin, L. and Bera, A. (1998), "Spatial Dependence in Linear Regression Models". In Ullah, A. and Giles, D. (Eds.), Handbook of Applied Economic Statistics, New York: Marcel Dekker.

Anselin, L. and Florax, R.J.G.M. (Eds.) (1995), New Directions in Spatial Econometrics, Berlin: Springer.

Anselin, L. and Rey, S.J. (1991), "Properties of Tests for Spatial Dependence in Linear Regression Models", Geographical Analysis, 23 (2): 112-131.

Anselin, L., Bera, A., Florax, R.J.G.M. and Yoon, M. (1996), "Simple Diagnostic Tests for Spatial Dependence", Regional Science and Urban Economics, 26 (1): 77-104.

Arbia, G., Basile, R. and Piras G. (2005), "Using Spatial Panel Data in Modelling Regional Growth and Convergence", ISAE Working Paper No. 55, Rome: ISAE.

Arbia, G., Basile, R. and Salvatore, M. (2002), "Regional Convergence in Italy 1951-1999: A Spatial Econometric Perspective", ISAE Working Paper No. 29, Rome: ISAE. 
Arbia, Elhorst and Piras (2005), "Serial and Spatial Dependence in the Growth Process of EU Regions", Paper presented at the Workshop on Spatial Econometrics, Kiel Institute for World Economics, Kiel, April 8-9, 2005.

Arbia, G. and Piras G. (2005), "Convergence in Per-Capita GDP Across European Regions Using Panel Data Models Extended to Spatial Autocorrelation Effects", ISAE Working Paper No. 51, Rome: ISAE.

Arellano, M. (1988), “An Alternative Transformation for Fixed Effects Models with Predetermined Variables". Applied Economics Discussion Paper No. 57, Institute of Economics and Statistics, University of Oxford.

Arellano, M. and Bond, S. (1991), "Some Test Specification for Panel Data: Monte Carlo Evidence and an Application to Employment Equations", Review of Economic Studies, 58 (2): 577-297.

Arellano, M. and Bover, O. (1995), "Another Look at the Instrumental Variable Estimation of Error-components Models”, Journal of Econometrics, 68 (1): 29-51.

Azariadis, C. and Drazen, A. (1990), "Threshold Externalities in Economic Development", Quarterly Journal of Economics, 105 (2): 501-526.

Badinger, H., W. Müller and G. Tondl (2004), "Regional Convergence in the European Union (1985-1999): A Spatial Dynamic Panel Analysis”, Regional Studies, 38 (3): 241-253.

Barro, R.J. and Sala-i-Martin, X. (1991), "Convergence Across States and Regions", Brooking Papers on Economic Activity, 1990 (1): 107-182.

Barro, R.J. and Sala-i-Martin, X. (1992), "Convergence", Journal of Political Economy, 100 (2), 223-251.

Barro, R.J. and Sala-i-Martin, X. (1995), Economic Growth, New York: McGraw-Hill.

Basile, R. (2007), "Intra-distribution Dynamics of Regional per-capita Income in Europe: Evidence from Alternative Conditional Density Estimators", ISAE Working Paper No. 75, Rome: ISAE.

Baumol, W.J. (1986), "Productivity Growth, Convergence, and Welfare: What the Long-Run Data Show", American Economic Review, 76 (5): 1072-1085.

Baumont, C., Ertur, C. and Le Gallo J. (2003) "Spatial Convergence Clubs and the European Regional Growth Process, 1980-1995”. In: Fingleton B. (Ed.), European Regional Growth, Berlin: Springer.

Bernard, A.B. and Durlauf, S.N. (1995), “Convergence in International Output", Journal of Applied Econometrics, 10 (2): 97-108. 
Bernard, A.B. and Durlauf, S.N. (1996), "Interpreting Tests of the Convergence Hypothesis", Journal of Econometrics, 71 (1-2): 161-173.

Blundell, R. and Bond, S. (1998), "Initial Conditions and Moment Restrictions in Dynamic Panel Data Models", Journal of Econometrics, 87 (1): 115-143.

Bond, S., Hoeffler, H. and Temple, J. (2001), "GMM Estimation of Empirical Growth Models", CEPR Discussion Paper No. 3048. London: CEPR.

Breiman, L., Meisel, W. and Purcell, E. (1977), "Variable Kernel Estimates of Multivariate Densities", Technometrics, 19 (2), 135-144.

Bulli, S. (2001), "Distribution Dynamics and Cross-Country Convergence: A New Approach", Scottish Journal of Political Economy, 48 (2): 226-243.

Carmeci, G. and Mauro, L. (2002), "The Convergence of the Italian Regions and Unemployment: Theory and Evidence", Journal of Regional Science, 42 (3): 509-532.

Carree, M and Klomp, L. (1997), "Testing the Convergence Hypothesis: A Comment", The Review of Economics and Statistics, 79 (4): 683-686.

Caselli, F., Esquivel, G. and Lefort, F. (1996), "Reopening the Convergence Debate: A New Look at Cross-country Growth Empirics", Journal of Economic Growth, 1 (3): 363-389.

Cass, D. (1965), "Optimum Growth in an Aggregative Model of Capital Accumulation", Review of Economic Studies, 32 (3), 233-240.

Cellini, R. and Scorcu, A. (1997), "How Many Italys? What Data Show About Growth and Convergence Across Italian Regions, 1970-1991", Rassegna Lavori dell'ISCO, 14: 93-124.

Cheshire, P.C. and Hay, D.G. (1989), Urban Problems in Western Europe: An Economic Analysis, London: Unwin Hyman.

Cheshire, P.C. and Magrini, S. (2000), "Endogenous Processes in European Regional Growth: Convergence and Policy", Growth and Change, 31 (4): 455-479.

Cosci, S. and Mattesini, F. (1995), "Convergenza e Crescita in Italia: Un'Analisi su Dati Provinciali”, Rivista di Politica Economica, 85 (4): 35-68.

Daniele, V. (2002), "Divari di Sviluppo e Convergenza Regionale in Italia: Un Esame per il Periodo 1960-1998", Working Paper No. 09/2002, Dipartimento di Diritto dell'Organizzazione Pubblica, Economia e Società (DOPES), Catanzaro: University of Calabria "Magna Graecia".

De la Fuente, A. (2000), “Convergence Across Countries and Regions: Theory and Empirics”. CEPR Discussion Paper No. 2465, London: CEPR. 
De Siano, R. and D'Uva, M. (2006), "Is There A Club Convergence Among Italian Regions?", Istituto di Studi Economici Working Paper No. 01/2006, Naples: University of Naples "Parthenope".

Durlauf, S.N. (1996), “A Theory of Persistent Income Inequality", Journal of Economic Growth, 1 (1): 75-93.

Durlauf, S.N., Johnson, P.A. and Temple, J.R.W. (2005), "Growth Econometrics". In Aghion, P. and Durlauf, S.N. (Eds), Handbook of Economic Growth, Volume 1 (1), Amsterdam: Elsevier.

Durlauf, S.N. and Quah, D.T. (1999), “The New Empirics of Economic Growth". In Taylor, J. and Woodford, M. (Eds.), Handbook of Macroeconomics, Amsterdam: Elsevier.

Elhorst J. P. (2001), "Dynamic Models in Space and Time", Geographical Analysis, 33 (2): 119-140.

Elhorst, P. (2003), "Specification and Estimation of Spatial Panel Data Models", International Regional Science Review, 26 (3): 244-268.

Elhorst, J.P. (2005) "Models for Dynamic Panels in Space and Time - An Application to Regional Unemployment in the EU". Paper presented at Workshop on Spatial Econometrics, Kiel Institute for World Economics, Kiel, April 8-9, 2005.

Fabiani, S. and Pellegrini, G. (1997), "Education, Infrastructure, Geography and Growth: An Empirical Analysis of the Development of Italian Provinces", Temi di discussione No. 323, Rome: Bank of Italy.

Fagerberg, J. (1988), “International Competitiveness”, Economic Journal, 98 (391): 355-374.

Fagerberg, J. (1994), “Technology and International Differences in Growth Rates”, Journal of Economic Literature, 32 (3): 1147-1175.

Florax, R.J.G.M. and Nijkamp, P. (2005), "Misspecification in Linear Spatial Regression Models". In K. Kempf-Leonard (Ed.), Encyclopedia of Social Measurement, San Diego: Academic Press.

Forni, M. and Paba, S. (2000), "The Sources of Local Growth. Evidence from Italy", Giornale degli Economisti e Annali di Economia, 59 (1): 1-49.

Fotopoulos, G. (2006), "Nonparametric Analysis of Regional Income Dynamics: The Case of Greece", Economic Letters, 91 (3): 450-457.

Friedman, M. (1992), “Do Old Fallacies Ever Die?”, Journal of Economic Literature, 30 (4): 2129-2132.

Galor, O. and Zeira, J. (1993), "Income Distribution and Macroeconomics", Review of Economic Studies, 60 (1): 35-52. 
Gerschenkron, A. (1962), Economic Backwardness in Historical Perspective, Cambridge MA: Belknap.

Getis, A. and Ord, J. K. (1992), "The Analysis of Spatial Association by the Use of Distance Statistics”, Geographical Analysis, 24 (3), 189-206.

Grossman, G.M. and Helpman, E. (1990), "Comparative Advantage and Long-Run Growth", American Economic Review, 80 (4): 796-815.

Hsiao, C. (1986), Analysis of Panel Data, Econometric Society Monographs, Cambridge: Cambridge University Press.

Hyndman, R.J., Bashtannyk, D.M. and Grunwald, G.K. (1996) "Estimating and Visualizing Conditional Densities", Journal of Computational and Graphical Statistics, 5 (4): 315-336.

Hyndman, R.J. and Yao, Q. (2002), "Nonparametric Estimation and Symmetry Tests for Conditional Density Functions”, Journal of Nonparametric Statistics, 14 (3): 259-278.

ISTAT (1997), I Sistemi Locali del Lavoro 1991, Rome: ISTAT.

Johnson, P.A. (2000), "A Nonparametric Analysis of Income Convergence Across the US States”, Economic Letters, 69 (2): 219-223.

Johnson, P.A. (2005), "A Continuous State Space Approach to "Convergence by Parts"”, Economic Letters, 86 (3): 317-321.

Koopmans, T. (1965), "On the Concept of Optimal Economic Growth". The Econometric Approach to Development Planning, Amsterdam: North-Holland.

Lichtenberg, F.R. (1994), "Testing the Convergence Hypothesis", The Review of Economics and Statistics, 76 (3): 576-579.

Loddo, S. (2006), "Structural Funds and Regional Convergence in Italy" CRENoS Working Paper No. 2006/03, Cagliari: CRENoS.

Loftsgaarden, D.O. and Quesenberry, C.P. (1965), "A Nonparametric Estimate of a Multivariate Density Function”, The Annals of Mathematical Statistics, 36 (3): 1049-1051.

Lucas, R.E. (1988), "On the Mechanics of Economic Development", Journal of Monetary Economics, 22 (1): 3-42.

Magrini, S. (1999), "The Evolution of Income Disparities among the Regions of the European Union”, Regional Science and Urban Economics, 29 (2): 257-281.

Magrini S. (2004), "Regional (Di)Convergence". In Henderson, J.V. and Thisse J.F. (Eds.), Handbook of Regional and Urban Economics, Volume 4, Amsterdam: Elsevier. 
Mankiw, G.N., Romer, D. and Weil, D.N. (1992), "A Contribution to the Empirics of Economic Growth”, Quarterly Journal of Economics, 107 (2): 407-437.

Morgani, P. and Ricciuti, R. (2001), "Further Evidence on Convergence Across Italian Regions", Paper presented at the XL Congress of the European Regional Science Association (ERSA), Zagreb, August 29 - September 01, 2001.

Murphy, K.M., Shleifer, A. and Vishny, R.W. (1989), "Industrialization and the Big Push", Journal of Political Economy, 97 (4): 1003-1026.

Nickell, S. (1981), "Biases in Dynamic Models with Fixed Effects", Econometrica, 49 (6): 1417-1426.

Overman, H.G. and Ioannides, Y.M. (2001), "Cross Sectional Evolution of the US City Size Distribution", Journal of Urban Economics, 49 (3): 543-566.

Paci, R. and Pigliaru, F. (1997), "Structural Change and Convergence: An Italian Regional Perspective", Structural Change and Economic Dynamics, 8 (3): 297-318.

Paci, R. and Saba, A. (1998), "The Empirics of Regional Economic Growth in Italy, 19511993”, International Review of Economics and Business, 45 (3): 515-542.

Pellegrini, G. (2002), "Proximity, Polarization, and Local Labor Market Performances", Network and Spatial Economics, 2 (2): 151-173.

Quah, D.T. (1993), "Empirical Cross-section Dynamics in Economic Growth", European Economic Review, 37 (2-3): 426-434. (a)

Quah, D.T. (1993), "Galton's Fallacy and Tests of the Convergence Hypothesis", Scandinavian Journal of Economics, 95 (4): 427-443. (b)

Quah, D.T. (1996), "Empirics for Economic Growth and Convergence", European Economic Review, 40 (6): 1353-1375. (a)

Quah, D.T. (1996), "Convergence Empirics Across Economies with (Some) Capital Mobility", Journal of Economic Growth, 1 (1): 95-124. (b)

Quah, D.T. (1996), "Ideas Determining Convergence Clubs". LSE Economics Department Working Paper, London: London School of Economics. (c)

Quah, D.T. (1997), "Empirics for Growth and Distribution: Stratification, Polarization, and Convergence Clubs". Journal of Economic Growth, 2 (1): 27-59.

Ramsey, F. (1928), “A Mathematical Theory of Saving”, Economic Journal, 38 (152): 543559.

Rey S.J. and Montuori, B.D. (1999), "US Regional Income Convergence: A Spatial Econometric Perspective”, Regional Studies, 33 (2): 143-156. 
Romer, P. (1986), "Increasing Returns and Long Run Growth", Journal of Political Economy, 94 (5): 1002-1037.

Romer, P. (1990), "Capital, Labor and Productivity", Brookings Papers on Economic Activity: Microeconomics: 337-367. (a)

Romer, P. (1990), "Endogenous Technological Change”, Journal of Political Economy, 98 (5): S71-S102. (b)

Romer, P. (1993), "Idea Gaps and Object Gaps in Economic Development”, Journal of Monetary Economics, 32 (3): 543-573.

Sain, S.R. (2002), "Multivariate Locally Adaptive Density Estimation", Computational Statistics and Data Analysis, 39 (2): 165-186.

Sain, S.R., Baggerly, K.A. and Scott, D.W. (1994), "Cross-validation of Multivariate Densities”, Journal of the American Statistical Association, 89 (427): 807-817.

Sain, S.R. and Scott, D.W. (1996), "On Locally Adaptive Density Estimation”, Journal of the American Statistical Association, 91 (436): 1525-1534.

Sala-i-Martin, X. (1996), "Regional Cohesion: Evidence and Theories of Regional Growth and Convergence", European Economic Review, 40 (6), 1325-1352.

Scott, D.W. (1985), "Averaged Shifted Histograms: Effective Nonparametric Density Estimators in Several Dimensions", The Annals of Statistics, 13 (3): 1024-1040.

Scott, D.W. (1992), Multivariate Density Estimation: Theory, Practice and Visualization. New York: Wiley.

Silverman, B.W. (1986), Density Estimation for Statistics and Data Analysis, London: Chapman and Hall.

Solow, R. M. (1956), "A Contribution to the Theory of Economic Growth", Quarterly Journal of Economics, 70 (1): 65-94.

Swan, T.W. (1956), "Economic Growth and Capital Accumulation", Economic Review, 32 (2): 334-361.

Terrell, G.R. and Scott, D.W. (1992), "Variable Kernel Density Estimation", Annals of Statistics, 20 (3): 1236-1265.

Vamvakidis, A. (2003), "Regional Convergence in Italy: 1960-2002", In International Monetary Fund, IMF Country Report No. 03/352, Washington D.C.: IMF. 
Wand, M.P. and Jones, M.C. (1993), "Comparison of Smoothing Parametrizations in Bivariate Kernel Density Estimation", Journal of the American Statistical Association, 88 (422): 520-528.

Wand, M.P. and Jones, M.C. (1994), "Multivariate Plug-in Bandwidth Selection", Computational Statistics, 9(2): 97-116.

Wand, M.P. and Jones, M.C. (1995), Kernel Smoothing, London: Chapman and Hall. 